\title{
El Fondo Gestoso en la Biblioteca Capitular Colombina

\author{
Historia y descripción
}

\author{
Nuria Casquete de Prado Sagrera \\ Directora gerente de la Institución colombina
}

\begin{abstract}
Resumen: La inmensa labor desarrollada por José Gestoso y Pérez (1852-1917) en torno al patrimonio cultural hispalense durante toda su vida, lo han convertido en una de las más importantes figuras de su generación.

Donó sus libros y su colección de cartas y otros documentos a la Biblioteca Capitular Colombina de Sevilla. Este artículo estudia la estructura y contenido de ese legado, desde las tareas de organización previas a su entrega al Cabildo Catedral hasta las labores de conservación y descripción desarrolladas en la actualidad.
\end{abstract}

\begin{abstract}
The inmense labour developed by José Gestoso y Pérez (1852-1917) about the sevillian cultural heritage during his entire life, have made him become one of the most important figures within his generation.

He donated his books, collection of letters and other documents to the Biblioteca Capitular Colombina of Seville. This article studies the structure and content of that legacy, which involves organizational tasks previous to their delivery to the Caathedral Chapter, and also, other preservation and description labours which are developed nowadays.
\end{abstract}

En estudios anteriores he ido presentando la figura y obra del historiador, arqueólogo y literato sevillano José Gestoso Pérez, siempre en relación con la Catedral de Sevilla -de forma especial con la Biblioteca Capitular Colombina- y con el legado que le fue entregando tanto en vida como tras su fallecimiento en 1917, ${ }^{1}$

José Gestoso y Sevilla. Biografía de una pasión, Sevilla, ICAS, 2016; Dejando huella. José Gestoso, el Cabildo y la Catedral de Sevilla (1875-1917), en "Anuario de Historia de la Iglesia Andaluza" Vol. X (2017) 289-324, y José Gestoso y sus servicios en favor de la Biblioteca Colombina (en prensa). Para simplificar las citas no voy a remitir en cada caso a estos títulos cuando trate un asunto que puede aparecer en mayor o menor medida en ellos. El primero de ellos es una visión general de todos los asuntos relacionados con Gestoso y el tercero es el más vinculado a la Biblioteca Capitular Colombina. Este artículo podría considerarse como su segunda parte o, al menos, su continuación lógica. 
conocido como el Fondo Gestoso. Las páginas siguientes son un paso más en esta investigación, ya que se centran en el análisis de esa importante donación bibliográfica y documental recibida en la Biblioteca del Cabildo, de la cual hasta ahora sólo había un estudio parcial y la edición de algunos de sus documentos (ver Anexo 1). Veremos por tanto en qué consiste ese Fondo, desde que comenzaron las donaciones de libros hasta las tareas que actualmente se están desarrollando en la Biblioteca para mejorar su conservación, descripción y difusión.

Gestoso, llamado también por sus amigos el Licenciado por serlo en Derecho, donó en conjunto al Cabildo Catedral más de 1000 volúmenes, cifra que incluye impresos (folletos y monografías), manuscritos y tomos con documentos varios, siendo tal vez el legado mayor el realizado después de su muerte y, desde luego, el más conocido. Con él precisamente vamos a comenzar, acercándonos a cómo fue la preparación que requirió esta parte del legado antes de su entrega. Continuaremos con la descripción de los diversos formatos de los volúmenes que donó y de sus muy diversos contenidos, incluyendo las mencionadas labores actuales, que se insertan dentro de las actividades y publicaciones que están teniendo lugar este año 2017 en memoria de Gestoso al cumplirse el primer centenario de su fallecimiento. Este trabajo interno en la Biblioteca Capitular Colombina es sin duda el mejor homenaje que podemos ofrecer a esta singular figura de la cultura sevillana unido, lógicamente, a la exposición conmemorativa que el Cabildo Catedral hispalense ha celebrado recientemente en la propia basílica titulada La huella de José Gestoso en la Catedral de Sevilla, completada con otra más específica relacionada con el Archivo de la Catedral: José Gestoso Pérez (1852-1917). Un erudito entre papeles.

Antes de comenzar quisiera hacer una precisión. Según los términos de su testamento, lega a la Biblioteca Capitular de la Santa Iglesia Catedral de Sevilla denominada Colombina los manuscritos de su pluma, sus papeles históricos y literarios y de sus libros, todos los que posea en el momento de su muerte excepto aquellos de que existan ya ejemplares en dicha Biblioteca. ${ }^{2}$ Sin embargo, no por ello debemos pensar que, salvo esos títulos repetidos, todos los libros y documentos de Gestoso se conservan en la Catedral. A pesar del enorme volumen de correspondencia (6.178 según el acta de entrega), en ella vemos claras -y a veces lógicas- ausencias, como las correspondientes a asuntos familiares. No hay por ejemplo cartas de su padre o de su hermano Luis, ni otras que sin duda existieron sobre ciertos asuntos privados. Tampoco están todos sus diplomas ni recuerdos, como los cuadernos del colegio que menciona -y que por tanto vioMaría Daguerre Dospital, ${ }^{3}$ ni los informes y notas que le remitían sus amigos

2 Cláusula séptima del testamento de José Gestoso, según copia entregada por su viuda al Cabildo Catedral: Archivo de la Catedral de Sevilla (A.C.S.), Fondo Capitular, Sec. I, Correspondencia, leg.11.191 expte. 17.

3 Según recoge en la presentación que redacta a la ed. de 1918 de la Guía Artística de Sevilla de Gestoso, p. III. 
como ellos mismos comentan en sus cartas. En cuanto a su biblioteca, una parte quedó en la familia, donde aún se conservan, y otra, presumiblemente los títulos repetidos en la Capitular, están en la Universidad.

Como se irán mencionando desde el primer momento los distintos tipos de libros que constituyen el Fondo Gestoso, los resumo a continuación para que el lector tenga una visión general. El Licenciado donó en vida sobre todo monografías y algunos tomos de Papeles Varios, pero su legado posterior estuvo compuesto por monografías, que suponen algo más de la mitad del total de volúmenes donados entonces, y por los siguientes tomos facticios:

- 174 tomos de Papeles Varios impresos (aunque en ocasiones incluyan algún manuscrito) en tres tamaños: $8^{\circ}$ (62 vols.), $4^{\circ}$ (78) y $2^{\circ}$ (34). La encuadernación de todos ellos es en holandesa con lomos y puntas en piel roja.

- 41 tomos de Papeles Varios manuscritos e impresos en tamaño gran folio encuadernados en pergamino.

- 16 tomos de Apuntes, también con encuadernación holandesa en rojo.

- También fueron así encuadernados los 23 tomos de Correspondencia.

Hay, además,

- Cuatro legajos de Autógrafos,

- Las Memorias de Gestoso tituladas De historia sevillana. Páginas de mi vida, en dos volúmenes, y

- Tres tomos donados en 1941 por su hija Paz en los que se recogen Títulos honoríficos recibidos por su padre a lo largo de su vida (2 vols.) y otro íntegramente dedicado a Méritos y Servicios relacionados con el Ayuntamiento hispalense. A pesar de esta distinción, suelen denominarse los tres como Títulos Honoríficos.

Todo este conjunto tan variopinto fue donado por Gestoso desde 1875, primera fecha conocida de una donación suya hasta 1923, año en que concluyó la entrega de su legado por parte de su viuda.

\section{PREPARACIÓN DEL FONDO GESTOSO. LA LABOR DE MARÍA DAGUERRE DOSPITAL}

Quien se encargó tras la muerte de Gestoso de cumplir su última voluntad respecto a sus libros y documentos fue su viuda, María Daguerre Dospital y Buisson (1860-1931), uno de los albaceas de su marido. Preparó y entregó su legado a la Biblioteca fiel y cumplidamente como ahora veremos. Tan exhaustiva fue su labor que merece ser recordada porque no parece que todos los tomos que quería entregar el Licenciado a la Biblioteca estuvieran encuadernados ni identificados en el momento de su muerte. De hecho, Gestoso prevé en su testamento que 
como es posible que al ocurrir mi muerte no tenga encuadernados mis manuscritos, les estimaré (a su familia) que los manden encuadernar, para que no se diseminen ni pierdan. María hizo mucho más que eso, pues no sólo encuadernó, sino que además folió, inventarió, cotejó e incluso añadió sus propios comentarios a cartas y escritos, revelando en ellos el íntimo conocimiento que tenía de los asuntos de Gestoso y de las personas que éste conocía.

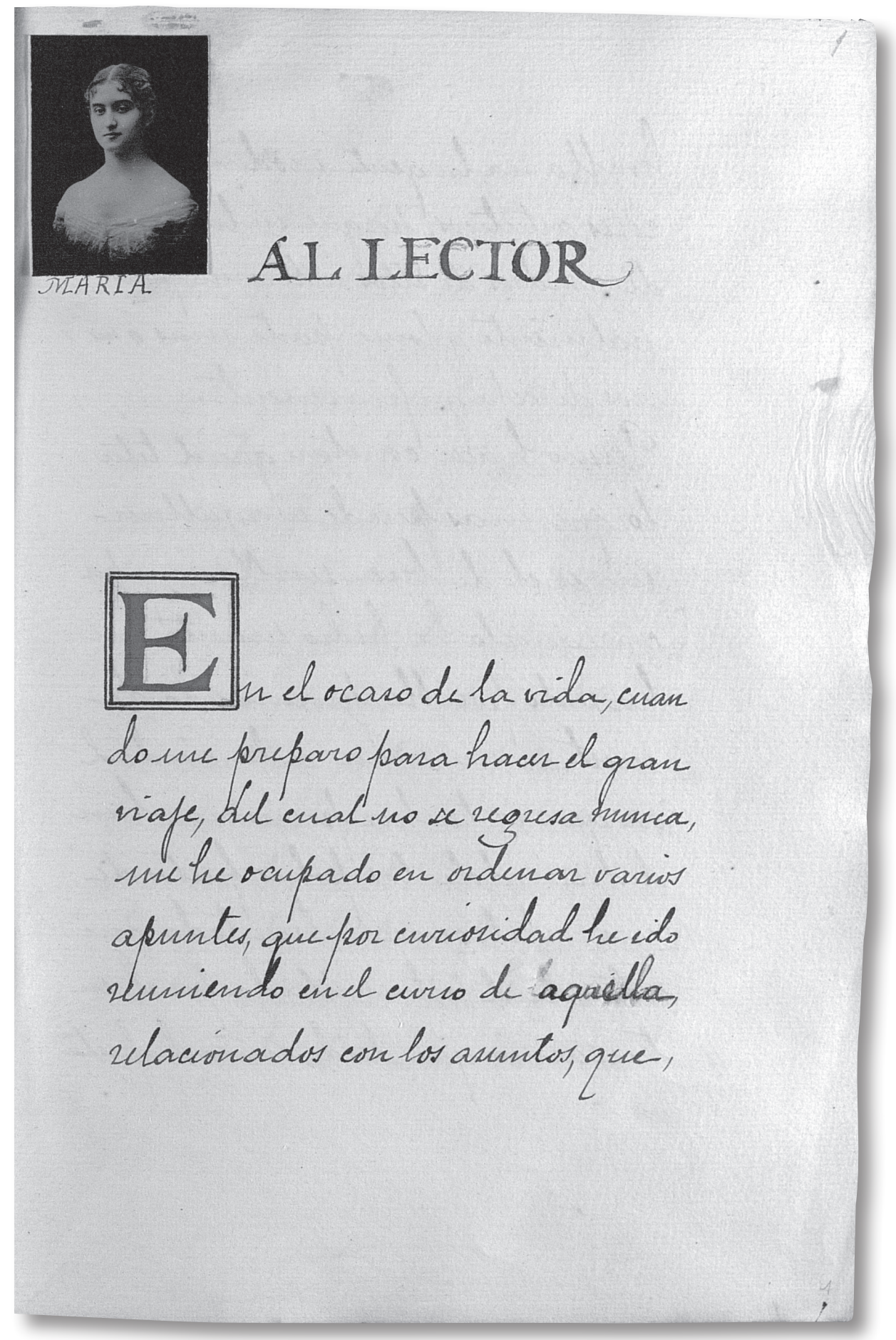

Figura 1. Primera hoja de las Memorias de Gestoso con fotografía de María Daguerre Dospital. (C) Cabildo Catedral de Sevilla. 
Respecto a lo primero, ¿cuáles fueron esos manuscritos que había que encuadernar? ¿tal vez los dos tomos de sus Memorias? ¿los Apuntes? ¿o los de Correspondencia? Es difícil saberlo, pero algo sí podremos acercarnos. Parece que las cartas se venían encuadernando desde tiempo atrás, según se deduce de ésta que le escribe en fecha tan temprana como 1891 su gran amigo el conde de las Navas: ¡Perdona monín! Me olvidaba de lo de la encuadernación y ahora me lo recuerda María cuando ya comenzaba a desobedecerte. Bien es verdad que el papel de esta epístola excede de la marca regular y puede que sólo por esto no esté destinado a inmortalizarse. ${ }^{4}$ Fue una preocupación innecesaria porque el tamaño excesivo de las cartas, y fueron muchos los casos, se solucionó con los más diversos plegados.

El encuadernador habitual de Gestoso, y muy conocido en Sevilla por entonces, era Luis Márquez y Echeandia. En realidad, es el único del que aparece una etiqueta en los volúmenes de Gestoso, porque cuando la hay siempre es suya o simplemente no hay ninguna. Están pegadas en el interior de las cubiertas de los libros y en ellas consta la dirección de su domicilio o taller. Como éste va cambiando a lo largo del tiempo, nos permiten seguir la propia cronología de las encuadernaciones, admitiendo que realmente en cada caso se utilizó la etiqueta correcta en ese momento y no una anterior. Si seguimos las noticias que aporta la siempre útil Guía oficial de Sevilla y su provincia, ${ }^{5}$ estuvo Márquez desde 1884 en la calle Génova nº 5 y 7 (llamada a partir de 1898 Cánovas del Castillo, también con cambio en la numeración: 7 y 9), pasando a la calle Hernando Colón 32 desde 1913. En 1920 nos encontramos que no sólo hay cambio de domicilio (que pasa a estar en Mateos Gago 46-52) sino también de nombre, porque constarán entonces como encuadernadores los Hermanos Márquez y más adelante como Hijos de Luis Márquez. Si bien en vida de su padre no podemos tener certeza del uso exacto de las etiquetas con la dirección correcta, sin embargo cuando aparece la dirección de Mateos Gago no cabe duda que el volumen fue encuadernado después de 1917, por tanto tras la muerte de Gestoso. Lo que ya es imposible concretar es lo que pudo encuadernar Luis Márquez cuando estaba en la calle Hernando Colón (1913-1919) antes y desde la muerte de Gestoso (1917).

Partiendo de esta base, el resultado de una revisión de las etiquetas en las encuadernaciones del Fondo Gestoso ha sido el siguiente: si empezamos por los tomos de Papeles Varios impresos -todos ellos, en 8, $4^{\circ}$ y folio-, parece que fueron prácticamente todos encuadernados por el propio Luis Márquez. No olvidemos que el propio Gestoso menciona los manuscritos como los libros que pueden no estar encuadernados a su muerte, no los impresos. Aunque suelen sucederse correctamente los cambios de dirección, hay curiosas excepciones, como la

B.C.C., Fondo Gestoso (F.G.), Correspondencia, 1891-92, nº 61.

Esta Guía fue publicada desde 1865 por Manuel Gómez Zarzuela y continuada por su hijo Vicente desde 1888. 
etiqueta de la calle Mateos Gago (es decir, a partir de 1920) precisamente en el primer tomo primero en tamaño $4^{\circ}$ y ya no habrá más etiquetas hasta el tomo 31, que llevará la dirección de Génova (1884-1898). En los volúmenes en 8ºn medio de volúmenes encuadernados en este periodo hay otros con la etiqueta ya de Cánovas del Castillo (t. 9 ${ }^{a}$ o 18-18), siendo el sello a partir del t. 29 el de Hernando Colón, salvo el tomo 41 que es el de Cánovas del Castillo. También hay una cierta correlación cronológica en los tomos de Papeles Varios manuscritos e impresos.

En los de Apuntes falta casi siempre el sello del encuadernador, sólo está en los tomos 10 y 11, con la dirección de Génova, y en el T. II el de Mateos Gago. En cuanto a la Correspondencia, hay una evidente mezcla en el momento en que fueron encuadernados a tenor, siempre, del sello del encuadernador. Así, el primer tomo fue encuadernado por los hijos de Márquez, por tanto tuvo que ser entre 1920 y hasta 1921 por ser éste el año en que la viuda entregó las cartas a la Biblioteca. También encuadernaron los tomos correspondientes a 1907-8 y desde 1911 a 1914. El resto ya lo había encuadernado su padre pero sin seguir un orden lógico. Incluso en un caso, el tomo“2 1910"lleva dos sellos: de Hernando Colón y de Mateos Gago.

Las Memorias llevan el sello de la calle Hernando Colón (entre 1913-1919). Como tienen anotaciones hasta 1915 pudieron ser encuadernadas en vida de Gestoso. Debe ser lo más probable, ya que se conservaban en una caja de nogal a medida con una llave de la que pende una pequeña cartela en la que aún hoy podemos leer, con letra de Gestoso, "caja de mis papeles". En ella fueron entregados y sellados los dos tomos hasta su apertura en 1980 y la caja siguió conservándose, aunque vacía, en la Biblioteca Capitular Colombina.

Por último, nos quedaría hablar de las monografías donadas por Gestoso. Sus encuadernaciones son muy variadas ya que algunas conservan la suya original y otras fueron reencuadernadas por el Licenciado, llevando en ocasiones el sello de Márquez. Como podemos ver en varios ejemplares donados a la Biblioteca, parece que recurría a él para encuadernar sus propias obras -o las de otros autores- en piel o tela con su característico escudete y, en contados casos, incluso en pergamino, como su manuscrito original de la Historia de los barros vidriados o unas obras de José María Asensio y Benito Mas y Prat que curiosamente son sin duda las más lujosas de las que se conservan en su legado. También procedía así antes de regalar títulos suyos, o al menos en alguna ocasión, como se desprende de una carta de su amigo José Valdenebro y Cisneros en la que le comunica que Hace unos días trajeron de casa de Márquez cuatro ejemplares de su interesante tomo $3^{\circ}$ del Diccionario, es uno para mí que agradezco a V. mucho y los otros sin duda para el Registro de la Propiedad. ${ }^{6}$ Tal vez Gestoso actuara a veces como intermediario entre el encuadernador y sus amigos, ¿o cómo interpretar si

$6 \quad$ B.C.C., F.G., Correspondencia, $1^{\circ} 1909$, nº 55. 
no esta carta de Francisco Rodríguez Marín? En ella le dirá que está de acuerdo con lo dispuesto sobre las encuadernaciones y que habrá V. recordado a Márquez que ha de dejar intonsos los cuatro libritos, cortándoles muy poco de la cabeza, único canto que ha de dorar. ${ }^{7}$ Ya que está dando instrucciones, debía ser un encargo suyo y no un regalo de Gestoso.

Con todo esto podemos concluir que en su mayoría el Fondo Gestoso fue encuadernado por su propio dueño, completado después por María Daguerre en casos muy puntuales, como en el caso de los Papeles Varios impresos, Correspondencia y Apuntes.

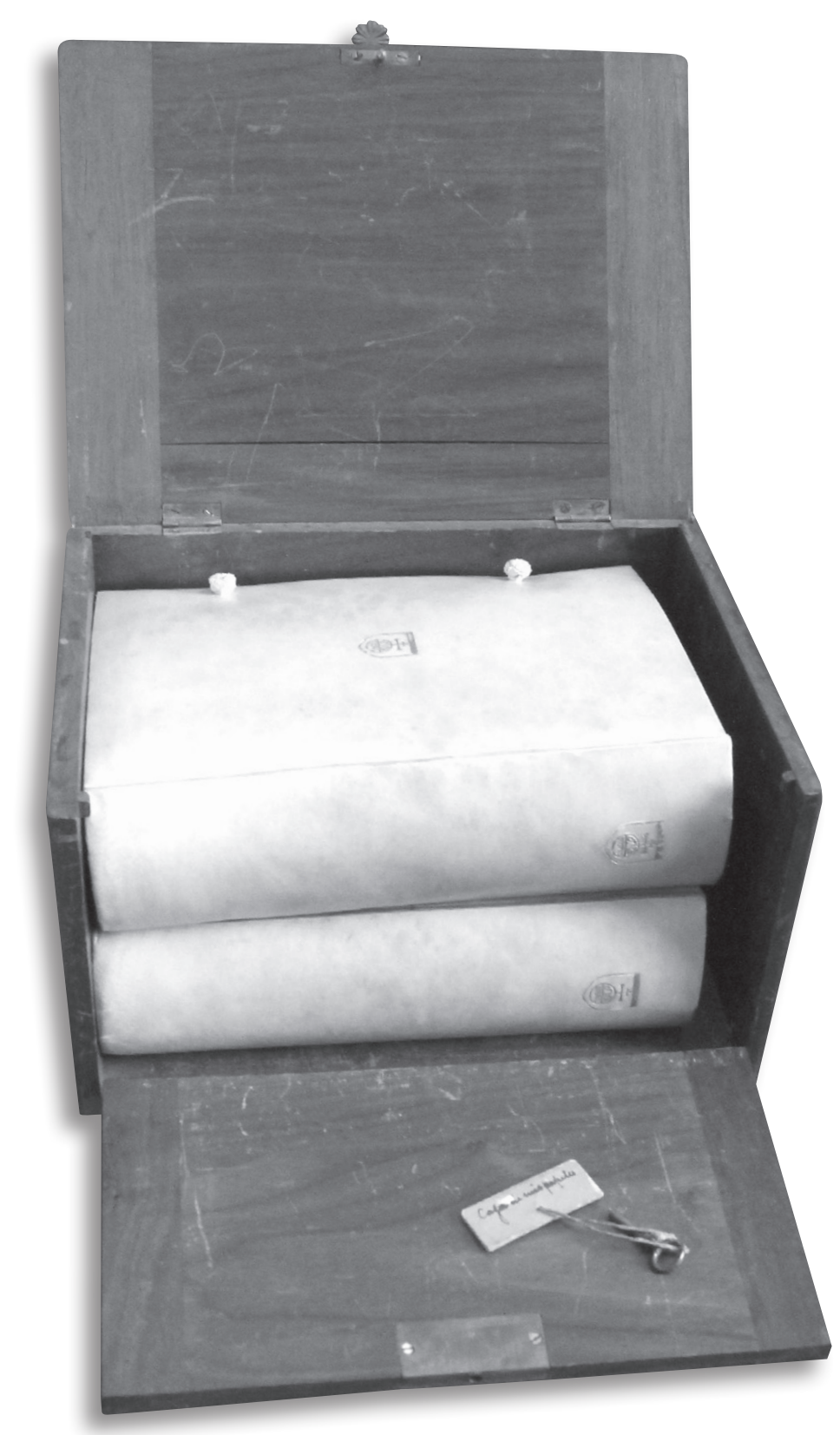

Figura 2. Caja donde Gestoso guardaba sus Memorias. (CAna Isabel Gamero.

$7 \quad$ B.C.C., F.G., Correspondencia, 1893-94, nº 68 (16 de mayo de 1893). 
Además de encuadernar, en realidad el único encargo de Gestoso que nos consta, su viuda hizo mucho más. Por lo que se deduce de sus notas, y siempre -salvo contadas excepciones- en tinta roja, folió los tomos de Papeles Varios manuscritos e impresos, de Correspondencia y de Apuntes. Al hacerlo, en alguna ocasión María cometió errores de foliación, encontró otros de encuadernación o descubrió alguno de Gestoso que anotaba en el propio documento con un característico ¡Ojo! seguido de la advertencia correspondiente. Veamos algunas de esas llamadas de atención:

- ¡Ojo! Equivocada la foliación. Del 190 pasé distraída al 200, no faltan folios. $M D D{ }^{8}$

- ¡Ojo! Este folio no ocupa el lugar que le corresponde por error de encuadernación M.D.D. ${ }^{9}$

- Identificará la portada de un impreso encuadernada después del propio texto con un: ojo véase el f. 444 que parece carp ${ }^{a}$ de este impreso. ${ }^{10}$

- En cuanto a fallos relacionados con el Licenciado, podemos encontrar aclaraciones como éstas: Se han marcado con * los lugares que ocupan fotografías y artículos que se hallan fuera de Yndice y de paginación y también aquellos números en que existe error entre las páginas que ocupan y las indicadas en el "Yndice"; Este índice está equivocado desde el número 5 al 30. La foliación correlativa $M D D .{ }^{11} \mathrm{Y}$ abundará en ello pero no en el tomo sino en el Inventario que hizo de él, incluyendo esta otra nota: Faltan los números 19 y 29. La primera falta la anota el Sr. Gestoso pero no la segunda.

- En la portadilla del doc. 27 (f. 123) del tomo de Papeles Varios XXX, sobre Papeles referentes a la Guerra de la Independencia ochenta y tres documentos, anotará: Aunque bajo la indicación de "Franceses" (que hemos respetado) compréndese en el Yndice de este tomo desde el folio 124 al 360 inclusive, debemos hacer constar que no todos los papeles contenidos en esta carpeta tienen relación con ellos ni con la Guerra de la Independencia aunque sí con su época. Veanse entre otros los fols. 165 y 167 M.D.D."12

Este recurso había sido también utilizado en diversas ocasiones por Gestoso, aunque más bien en comentarios al margen en obras de otros autores o en borradores que, según parece, enviaba a la imprenta y en los que hacía

8 B.C.C., F.G., Apuntes T. 7 h. 200. De este tipo de error se podrían poner otros varios ejemplos: Apuntes T. 3 h. 150; Correspondencia 1891-1892, no 105 2a, 1895-1898, nº $1522^{\mathrm{a}}$ o PP.VV.T. XXXIII, $n^{\circ} 41$ f.260. En Apuntes T. 1 h. 60 precisará que falta por error el f. 59 pero"el texto está íntegro".

9 B.C.C., F.G., Apuntes T. 6 h. $57 \mathrm{v}$.

10 B.C.C., F.G., PP.VV. T. XXXV n 21 h. 367.

11 Notas en los índices de: B.C.C., F.G., PP.VV. T. II y III respectivamente.

12 Otros ejemplos: en el tomo XXXIII no 63, h. 474 escribirá: Bajo esta misma carpeta, Papeles, Subasta y Cuentas referentes al derribo de la torre, y en el T. XXXVII n ${ }^{\circ} 3, h$. 137, dirá que aparte de los autógrafos recogidos en el listado inicial hay algunos más después del que lleva el $n^{\circ} 1$ y para evitar confusiones sin alterar la numeración, los hemos señalado con $n 11^{20} \mathrm{y} \mathrm{n}^{\circ} 1^{30}$. 
algunas indicaciones, como éstas: Ojo, lo que está rodeado de lápiz no se compone" y "Ojo componer nada más que hasta la *.13

No cabe duda que los tomos encuadernados en pergamino de Papeles Varios manuscritos e impresos, los más conocidos, ya lo estuvieron -o al menos en su mayoría- en vida de Gestoso, porque en varias ocasiones él mismo dirá que ha quitado un documento, usando incluso el verbo "arrancar". Así, por ejemplo,

- En el T. I, en el lugar del n 19 nos encontramos un dibujo y nota de Gestoso en la h. 237v que dice así: Ojo: el papel no 19 que ocupaba este lugar lo remití a Barcelona con mi estudio titulado La Giralda Su pasado y su presente, y representaba al alminar según el cuadro de Sturmio: en su lugar he puesto el del cuadro de Alejo Fernández. ${ }^{14}$

- Según la nota en el T. III, h. 149: Aquí había un autógrafo de Felipe IV que he arrancado para mi colección de autógrafos. Gestoso, pasando así al T. XXXIX (tercero de autógrafos), doc. 13.

- Un último caso: en 1907 quitó el n 23 del T. XII, como así hace constar en su índice, por tratarse de un fragmento de un libro antiguo de la Real Maestranza hispalense que quiso regalar a esta institución.

Aunque el inventario de estos tomos de Papeles Varios los hiciera años después María, Gestoso tuvo mucho que ver en su formación. Hizo numerosas "carpetas artísticas" a los documentos, aparte de anotar en muchos de ellos su procedencia, identificación o descripción, fecha, etc. María también llamará "carpeta" a lo que hoy sin duda conocemos por"portadilla", ya que se trata sólo de una hoja, habitualmente con el título del documento o texto al que precede, acompañado a veces por alguna otra anotación, como su procedencia. Esas portadas suelen tener letra de Gestoso, pero al menos en un tomo de estos Papeles Varios, en concreto en el XXIX, había un papelillo suelto en el documento $n^{\circ} 5$ con letra que parece de María y en su característica tinta roja que decía: En este tomo poner carpetas y numerar cartas antes de enviarlo a la Colombina, lo que hace pensar que fue ella quien lo mandó encuadernar. Sin embargo, si nos fijamos bien, esas hojas están pegadas a los documentos, por lo que bien pudo hacerse la operación ya encuadernados los documentos, aunque requirió verdadera habilidad. Al faltar la etiqueta del encuadernador no contamos con más información para precisar este dato.

Algunas de sus notas sugieren que María se preocupó no sólo preparar y describir el legado de Gestoso sino que además investigó algunos datos o, al menos, la lectura de los documentos le sugirieron hacerlo, como en este caso: Cuando haya tiempo confrontar fechas construcción y reparos, advierto en ellas confusión, o

13 B.C.C., F.G., Apuntes T. 3, h. 181 y 295. En la obra de Celestino López Martínez Valdés Leal y sus discípulos. Sevilla, 1907, hay muchos "ojo" de Gestoso en notas marginales (PP.VV. 4 T. 37, n²).

14 B.C.C., F.G., PP.VV.T. I n 19 f. 238. 
bien relaciona información: véase el folleto de Pierre de Fontenilles tom 13 de PPVV en $4^{\circ}$. Cita al Ldo. Gestoso paga 7 Sevilla Monumental en las notas. ${ }^{15}$

Tras esta labor, o paralelamente a ella, describió en seis inventarios el legado de Gestoso agrupándolo en las distintas tipologías que ya hemos visto en función de su contenido y dentro de éste, en el caso de los Papeles Varios impresos, por su tamaño $\left(8^{\circ}, 4^{\circ}\right.$ y $2^{\circ}$ o folio). Los otros tres inventarios los dedicó a las misceláneas encuadernadas en pergamino, aquí llamadas Papeles Varios manuscritos e impresos, a las monografías y un sexto que, aunque no nos ha llegado, debió estar dedicado a los tomos de Apuntes. La existencia de esos seis repertorios la aporta un acta capitular en la que se afirma que se habían entregado seis índices o catálogos que conteniendo oportunas observaciones y copia de datos bibliográficos han sido formados con prolijo esmero por la expresada Sra. viuda. ${ }^{16}$

Fue un trabajo lento. De hecho, la suma de la foliación, encuadernación e inventariación requirió varios años para completarlo. A falta de fuentes que lo corroboren, si nos guiamos por las portadas de los inventarios que se conservan en la Biblioteca Capitular Colombina (llamados por entonces índices), la llegada de los libros y papeles de Gestoso fue escalonada. Más adelante veremos en detalle esos repertorios, baste por ahora indicar cómo se sucedió la entrega. Los primeros tomos llegaron en junio de 1919. Se trataba de los Papeles Varios manuscritos e impresos. En el mes de enero de ese año aún anota María algunos comentarios en ellos, como en el t. XII, h. 433. Poco después, una carta revela que los libros al entrar en la Biblioteca eran revisados y probablemente cotejados con los índices que ella aportó, puesto que en un caso en este centro se detecta la falta del documento $\mathrm{n}^{\circ} 29$ del tomo III y se le comunicó a María, quien lo comprobó en el inventario que ella poseía en su casa. Hoy día en el lugar de ese documento está pegada una carta de María, sin fechar, dirigida a Rafael Núñez Alonso, presbístero y uno de los ayudantes de la Biblioteca:

Muy respetado señor mío. El otro día al volver de la Colombina me dediqué a examinar detenidamente los "Yndices" de los Fols. Ms. en busca del documento que faltaba en el T ${ }^{\circ}$ III. Encuéntrase en el T ${ }^{\circ}$ XXXIX ( $3^{\circ}$ de Autogs.) $n^{\circ} 2$ fol 7 y 8 . Sin duda fue desglosado también del lugar que ocupó para incorporarlo a los autógrafos, olvidando mi pobre Pepe (q gl. h) hacerlo constar así, como en el de Felipe IV. Es un perg ${ }^{\circ}$ escrito a fol ${ }^{\circ}$ tendido hasta la mitad con letra muy menuda y de fácil lectura. Tiene la doble curiosidad de la nota autoga de J. Gestoso del precio y dia en que lo adquirió en el Jueves y de ser citado por Zúñiga en sus Anales. Año 402 Fol 272. Está en mal estado y compuesto lo mejor que me ha sido posible. Creo que lo encontrará con estas indicaciones sin dificultad alguna. Tengo el gusto de remitir a V, como deseaba para esa Biblioteca, el Valdés Leal y la Guía Artística (última edición) Vea si en algo más puede procurarle la satisfacción de servir aV. a su at ${ }^{\mathrm{a}}$ ss q. respte. Iblm María D-DVda de Gestoso 10 de agosto.

15 B.C.C., F.G., Apuntes T. 10, nº 42, entre h. 323 y 324 y T. 11 n 50 respectivamente.

16 A.C.S., Fondo Capitular, Sec. I, Autos Capitulares, sign. 07280, h. 107 r y v y 122v. Se conserva un borrador del texto del acta de abril en: A.C.S., Fondo Capitular, Sec. I, leg.11.193 expte 14, s/f. 
Aunque sin datar, debió escribirla sobre el 11 de septiembre de 1919, fecha en la que consta el ingreso en la Biblioteca de las dos obras aquí mencionadas. Esta carta aporta otro dato curioso: según dice, el documento está en mal estado y compuesto lo mejor que me ha sido posible ifue sólo una acción concreta o era María quien solía "arreglar" los muchos documentos antiguos necesitados de cierta protección?

Casi un año después de la primera entrega, en 19 de marzo de 1920, llegaron a la Biblioteca Capitular las monografías y en agosto de ese mismo año los Papeles Varios impresos en tamaño $4^{\circ}$. Habrá ahora un breve paréntesis porque la siguiente entrada de libros no se incorporó a los estantes capitulares ya que se tratará del legado que debía permanecer clausurado hasta 1980: los tomos de Correspondencia, los de Autógrafos y las Memorias. En el cabildo celebrado el 30 de marzo de $1921^{17}$ se comunicaba que la viuda tenía ya preparada esta parte de la donación de José Gestoso, de la cual se hizo entrega, en tres cajas precintadas, en el mes de junio. Los volúmenes de la Correspondencia no fueron descritos sino simplemente numeradas las cartas, pero sin embargo podemos encontrar en ellas diversas e interesantes notas de María. Aunque la mayoría no llevan fecha, cuando ésta aparece lo hace hasta el mes de abril de 1921. La diversidad de notas fechadas en septiembre de 1920 y entre febrero y abril de 1921 en tomos de las más diversos años, desde el primero, con cartas de 1875 a 1885, hasta el de $1916,{ }^{18}$ revela que la viuda las leyó -o releyó- todas entonces y tal vez a la par las iba numerando. Algunos de sus comentarios son realmente ilustrativos. En ellos precisa quién es el corresponsal o qué hizo y qué opinión le merecía. A veces son textos extensos, como aquellos en que describe a dos amigos de Gestoso, Rodrigo Amador de los Ríos y Arturo Mélida. ${ }^{19}$ También son muy interesantes las notas sobre su propia familia, en especial acerca de su padre y sus hermanas. Otras veces incluye valoraciones sobre artistas y artesanos que trató el Licenciado, literatos, comentarios sobre el tema de los archivos de protocolos que tantos quebraderos de cabeza proporcionó a Gestoso, su proyecto de unas Memorias etc. o incluso sobre su propio marido, como en ésta de 1912: estuvo enfermo mi Pepe queridísimo larga temporada, con fiebres infecciosas que le debilitaron grandemente; o este otro: Este hecho es rigurosamente exacto, lo presenciamos en Chipiona Monast. de Nra. Sra. de Regla. De ella misma rara vez habla. Tal vez la nota más extensa a este respecto sea la que dedica a una labor que realizó durante meses sobre un tapiz de la Catedral en su propia casa. ${ }^{20} \mathrm{Tam}$ bién podemos encontrar interesantes notas suyas en la colección de Autógrafos.

17 A.C.S., Fondo Capitular, Sec. I, Autos Capitulares, sign. 07279, h. 226r.

18 A modo de ejemplo ver los siguientes tomos ordenados por la fecha de la nota: $1^{\circ} 1909, \mathrm{n}^{\circ} 95$ (En la actualidad Setbre. de 1920); 1916, n 66 (17 de febrero 1921); 1886-1888 nº 243 (12 de marzo de 1921); 1914, n 297 (15 de abril de 1921).

19 Por su extensión imposible insertar aquí. Ver Correspondencia 1914, nº 297 y 1899-1900, nº 4 respectivamente.

20 Respectivamente: B.C.C., F.G., Correspondencia 1912, nº 152; PP.VV.T. II, n91, p. 379 y Apuntes T. 7, h. 375 . 
Continuando con la llegada de libros a la Capitular, en diciembre de ese mismo año 1921 María entregó los Papeles Varios impresos en tamaño folio. Sabemos que le siguieron los de tamaño $8^{\circ}$ porque su índice lleva la indicación de "Cuaderno 5", aunque no está fechado.

Por último llegaron los tomos de Apuntes de los que ya se dijo no nos ha llegado inventario o noticia alguna. Su entrega debió ser en torno a marzo o primeros de abril de 1923, ya que en el acta capitular del 16 de abril se recoge la comunicación del bibliotecario de que ha sido completada la donación de Gestoso. Por otro lado, es en estos tomos donde encontraremos las notas más tardías de María, de 1922 y 1923, como ésta: Acabé el índice de este volumen hoy 27 de enero 1922 Laus Deo María D D Vda de Gestoso. Lo curioso es que se trata del tomo 6 y ese mismo día comenzó el del tomo 3 (1922 Viernes 27 enero empiezo el Yndice de este volumen), por lo tanto no seguía un orden riguroso, lo que significa que tuvo que hacer un borrador por tomo antes de que se pasaran por orden correlativo en limpio.

Finalmente, antes de entregarlos a la Capitular pegó en cada uno de los volúmenes, en cumplimiento de una de las disposiciones testamentarias de su marido, la siguiente etiqueta con el texto que también había dejado él redactado y que dice así: El Ldo. José Gestoso y Pérez donó este libro en prueba de cariño a la Biblioteca Colombina para aprovechamiento de los estudiosos. +26 septiembre 1917.

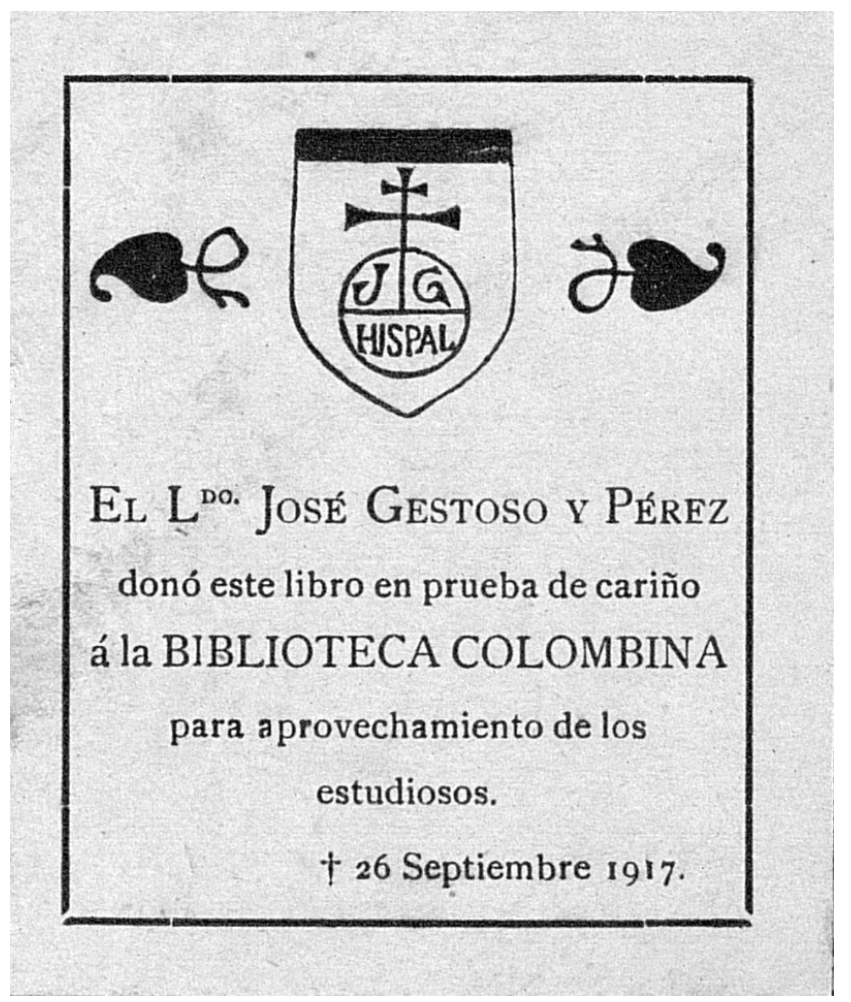

Figura 3. Etiqueta puesta en los libros que donó Gestoso tras su fallecimiento. (C) Cabildo Catedral de Sevilla. 


\section{ORGANIZACIÓN Y CONTENIDO DEL FONDO GESTOSO}

Gestoso había ayudado al arreglo de un nuevo salón en la Biblioteca Capitular Colombina en 1900, lo que le permitió contar con un espacio para los libros que iba donando, según era voluntad del propio Licenciado. Sin embargo, los distintos volúmenes que llegaron a la Biblioteca tras su fallecimiento, diecinueve años después, fueron ocupando los estantes disponibles que había en ese momento. Obviamente, mayor dificultad -por no decir imposibilidad- ofrecía poner junto a los anteriores los volúmenes que se encontraban en las cajas precintadas y que no fueron colocados en los estantes de la Biblioteca hasta 1980. Las signaturas que fueron recibiendo los libros nos revelan dónde fueron colocados a medida que se incorporaban a la Biblioteca. En su mayoría, los donados desde 1901, incluidos los

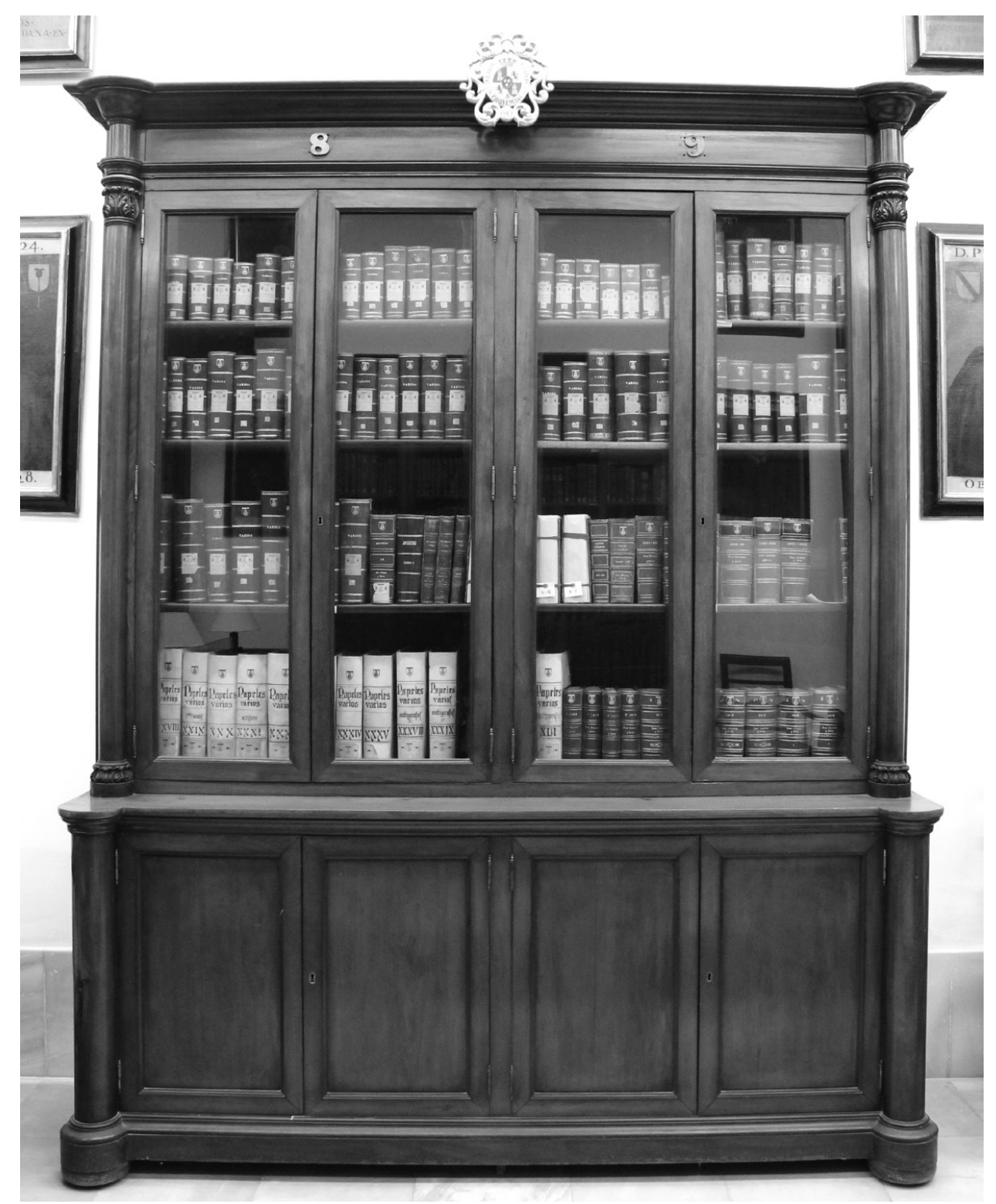

Figura 4. Uno de los armarios que custodia el Fondo Gestoso en la Sala de Lectura de la Biblioteca. (C) Ana Isabel Gamero. 
correspondientes a 1917, se distribuyeron en cinco armarios del salón nuevo, los $\mathrm{n}^{\mathrm{o}} 1$ al 5, curiosamente ocupando sobre todo las baldas 3 y 4 de casi todos ellos, aunque también se repartieron, en mayor o menor medida, por otras. Los anteriores, y estamos hablando de donaciones desde 1875, lógicamente se habían ya ido incorporando a armarios muy diversos: el 20, 22, 45, 58, 76, 109, 110, etc.

Los últimos volúmenes en ocupar un lugar en los estantes de la Biblioteca fueron los precintados en cajas hasta 1980 y ocuparon las baldas bajas de los armarios 113 y 114. Como era por entonces habitual, los libros se repartían en baldas a la misma altura de armarios contiguos para uniformar los tamaños. Así, todo este legado se fue disponiendo al final de la balda 6bis del armario 113 para continuar en la misma balda, 6bis, del armario 114. Curiosamente los tres tomos de Títulos Honoríficos que donó su hija Paz en 1941 ocuparon un lugar en el armario 3 del nuevo salón, balda 5, donde ya estaba buena parte de su legado.

Una de las disposiciones del testamento de Gestoso recogía su deseo de que los libros que ahora lega se conserven juntos con los ya donados, a ser posible en los mismos citados estantes y que si en ellos no cupieren se sitúen en otra sala de la Biblioteca, evitando su diseminación en distintos lugares. Esta postrera voluntad se cumplió en la medida que fue posible como ya hemos visto, pero realmente no ha podido cumplirse hasta ahora, cuando una vez conocido prácticamente todo el conjunto del Fondo Gestoso (es decir, lo hasta ahora identificado), se ha agrupado y reubicado en la Sala de Consulta de la Biblioteca Capitular Colombina. Con ello no sólo se ha pretendido hacer realidad aquella disposición de Gestoso, sino además hacerlo en esta Sala para facilitar su conocimiento y acceso a los investigadores. Es por tanto la primera vez que es posible contemplar toda la donación de Gestoso a la Biblioteca.

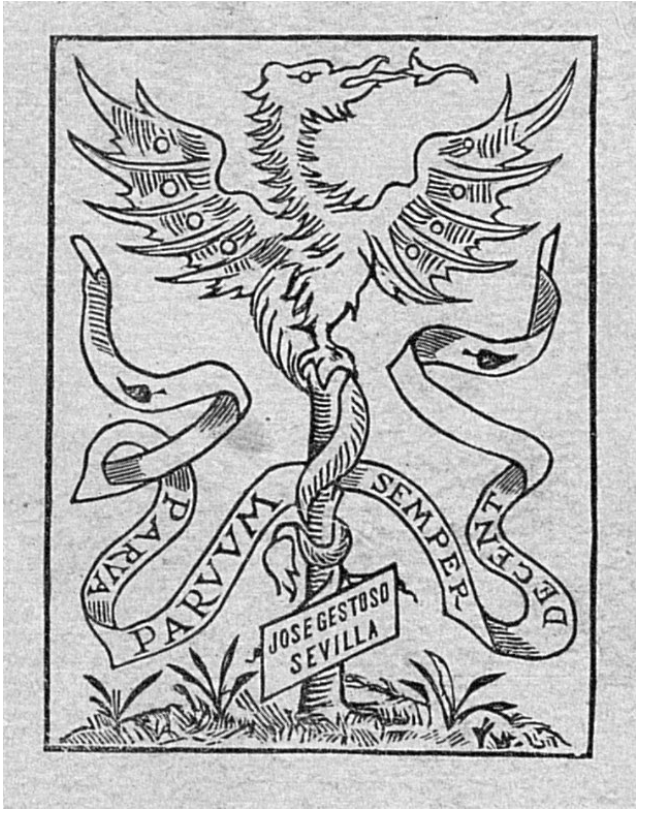

Figura 5. Ex libris de Gestoso. (C) Cabildo Catedral de Sevilla.

Antes de empezar la descripción del Fondo Gestoso quisiera comentar un detalle sobre los libros: la identificación de los que pertenecieron al Licenciado podemos hacerla en la mayoría de los casos, cuando se trata de los donados en 1917, gracias al tejuelo característico con el escudete con sus iniciales que él diseñó y cuyo texto ya se recogió al hablar de la labor de María Daguerre Dospital. Otros llevan un texto similar con la fecha de 1915.

Hay, además, un exlibris de Gestoso que aparece en algunas ocasiones, no muchas, independientemente del tejuelo de donación, y que al igual que el escudete, a veces lo incluye Gestoso en sus publicaciones, bien en portada, en el colofón 
o en la cubierta posterior. Se trata de la figura de un dragón sobre un tronco en torno al cual enrosca su cola mientras despliega unas enormes alas. Alrededor del tronco hay también una filacteria con uno de los lemas recurrentes de Gestoso: Parva paroum semper decent y, en la parte baja del tronco, una cartela conde aparece escrito "José Gestoso Sevilla". El tronco se asienta sobre una base que simula hierbas y plantas.

Por último, cabe consignar un sello seco que encontramos sobre todo en su colección de documentos y que consiste, una vez más, en su escudete con un diseño similar a como lo dibujó en la cubierta de Sevilla Monumental y Artística: algo inclinado hacia la izquierda, rematado por un yelmo y rodeado de lambrequines.

\subsection{Descripción del Fondo Gestoso}

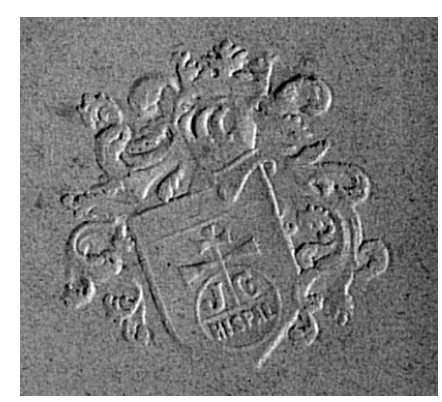

Figura 6. Sello seco de Gestoso. (C) Cabildo Catedral de Sevilla.

Entremos ya de lleno en comentar este legado. Veamos su volumen total, estado de conservación, medios de información disponibles, tanto antiguos como actuales, y copias digitales accesibles por los investigadores. En cada uno de estos puntos se incluirán datos de todos los grupos de libros. Para facilitar la consulta de cada uno de ellos, en el Anexo 2 se relacionan por separado, incluyendo la información específica acerca de su volumen, medios de información y copias digitales.

La extensión del legado de Gestoso es de 34 metros lineales, de los cuales no llegan a 5 los correspondientes al legado clausurado hasta 1980, es decir, la inmensa mayoría de él lleva abierto a la consulta pública desde 1923. Poco a poco se va completando la localización de algunas monografías recogidas en los distintos listados de donaciones conservados, tanto de 1901 como de 1904 y 1917. Los dos primeros son más difíciles de identificar porque en estos casos Gestoso no incluyó -o no lo hizo necesariamente- ninguna nota de donación, ni tejuelo u otra marca en la encuadernación que nos permita asegurar la procedencia del volumen. Por lo tanto, hay ejemplares en la Biblioteca localizados a través del fichero manual cuyo título y autor coinciden con los contenidos en estos listados pero no podemos asegurar que se trate del mismo ejemplar. A medida que avance la catalogación actual del fondo general de la Capitular, se irán identificando volúmenes a través de las dedicatorias, tejuelos u otro dato que nos permita reconocer su procedencia, libros donados en vida que no constan en ningún listado ni registro o bien títulos de Gestoso o libros de su biblioteca que donó a amigos y posteriormente ellos los legaron a la Capitular, como ocurre con José Cansino y Morón, Cayetano Segovia, José Cascales y Muñoz, etc. No forman desde luego parte del Fondo Gestoso pero sí nos ayudan a conocer mejor su vida, su biblioteca y su círculo de amistades. 
Las donaciones de 1901 y 1904 se han conocido recientemente al localizar en la Biblioteca los listados manuscritos correspondientes a ambas fechas y a la copia que del primero conservó Gestoso entre sus papeles, en concreto en el $\mathrm{n}^{\circ} 22$, f. 306 del T. XXVII de PP. VV.: Lista de las obras donadas a la Biblioteca Colombina en 10 de Mayo de 1901. En 1915 hizo una donación que debió tener cierta entidad al imprimir para ello una etiqueta en la que así constaba. Su texto era muy similar al que luego llevaría la de 1917: El Ldo. José Gestoso y Pérez donó este libro en prueba de cariño a la Biblioteca Colombina para aprovechamiento de los estudiosos. 1915. Sin embargo, ni en la Biblioteca ni en el propio legado de Gestoso se conserva noticia o listado alguno y por ahora son muy pocos los volúmenes identificados con esta etiqueta, no alcanzan la veintena, pero no tendría sentido imprimirla para tan poco número.

Vamos ahora a las cifras de ejemplares, comenzando por los volúmenes. En vida donó, al menos, 423 volúmenes, pero son los que tenemos identificados hasta ahora. El legado tras 1917 fue de 579 volúmenes, lo que hace un total de 1.002. En cuanto a títulos, si sumamos los contenidos en las misceláneas impresas, la cifra asciende a unos 352 en vida y 2.456 procedentes de su legado póstumo, en total unos 2.808. Sin embargo, no entran en esta cifra la correspondiente a los documentos y títulos de los textos comprendidos en sus tomos de Papeles Varios manuscritos e impresos, la Correspondencia, Apuntes, Autógrafos y Títulos honoríficos, pero estamos hablando de una cifra de varios miles, baste el dato de que las cartas son ya 6.178 y los folletos impresos 2.139.

El estado de conservación es en general bueno, aunque hay encuadernaciones dañadas en los tomos misceláneos que se están restaurando poco a poco, sobre todo los de la Correspondencia y los Apuntes. Más complejo es el estado de los documentos contenidos en los tomos de Papeles Varios manuscritos e impresos debido en unos casos a su antigüedad y en otros a sus muy diversos formatos, desde una tarjeta de visita a tamaños que pueden superar el A2, desde el pergamino al papel fotográfico, lo cual requiere una delicada restauración. Para preservar los originales se están digitalizando los documentos que pueden ser más demandados por los investigadores, evitando así una manipulación innecesaria.

María Daguerre Dospital acompañó la entrega de los volúmenes de Gestoso con seis "índices o catálogos", como se denominan en un acta del Cabildo, correspondientes a la parte del legado de acceso libre. Son descritos en los siguientes términos:

El Sr. Doctoral como bibliotecario de la Colombina dice, que la Sra. D ${ }^{a}$ María Daguerre-Dospital ha terminado la entrega total del legado que, según consta en el acta de la sesión del día 29 de enero 1918, dejó a la Biblioteca Capitular su difunto marido Excmo. Sr. Don José $\mathrm{M}^{\mathrm{a}}$ Gestoso y Pérez. Dicha entrega comprende 316 volúmenes impresos y 229 tomos de papeles varios; estos últimos 
se hallan distribuidos del modo siguiente: 41 volúmenes de gran folio, $78 \mathrm{id}$. en cuarto, 34 id. en folio, 62 id. en octavo y 14 en cuarto comprensivos éstos últimos de la colección de apuntes del dicho Sr. Gestoso. Todos los volúmenes se hallan minuciosamente descritos en los seis índices o catálogos que conteniendo oportunas observaciones y copia de datos bibliográficos han sido formados con prolijo esmero por la expresada Sra. viuda, y de los cuales índices autorizados con la firma de ésta y la del Sr. Canónigo Bibliotecario queda en la Biblioteca copia literal igualmente suscrita por ambas partes. Asimismo obra en el Archivo Capitular el acta autorizada por la Comisión que se nombró en el cabildo del día 30 marzo 1921 al hacerse por la mencionada Sra. viuda la entrega de las tres cajas que guardan bajo precinto cartas y manuscritos, comprendidas también en el legado de su difunto marido". ${ }^{21}$

Tal y como se mencionan aquí, no nos han llegado ninguno de esos inventarios. Contamos con cinco de ellos pero sin firma alguna. Están mecanografiados y hay, además, otros tres similares en cuanto a contenido pero manuscritos. Y también sin firmar. Contienen la descripción de los tres formatos de tomos de Papeles Varios impresos y llevan los títulos escritos en caracteres góticos, dos de ellos entre las dos hojas características que usaba Gestoso en sus publicaciones y encabezados todos por su escudete:

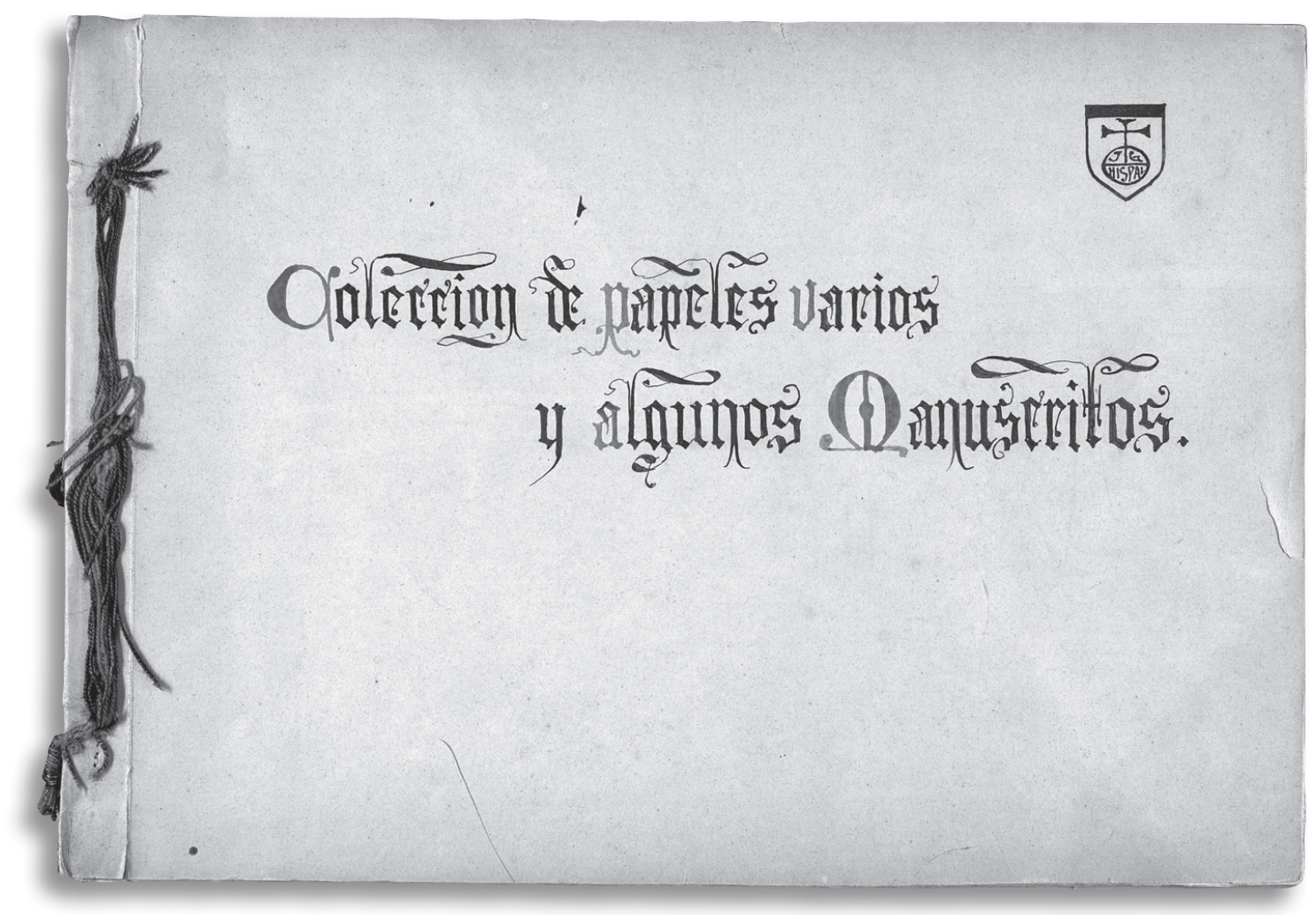

Figura 7. Inventario manuscrito de los Papeles Varios de Gestoso. (c) Cabildo Catedral de Sevilla.

21 Ver nota 15. 
- Colección de papeles varios y algunos manuscritos. En la primera hoja añade, a modo de título extenso, además de lo anterior, que tienen

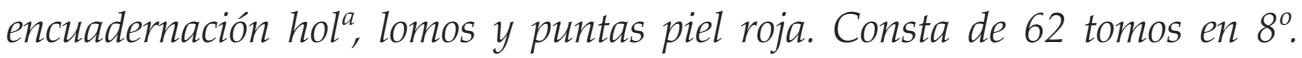
Dobles hasta el 19 inclusive. Hay n 9, 9² y 9A. Están numerados del 1 al 43 y contienen 553 títulos.

- Colección de P.P.V.V. impresos y algunos manuscritos, encuadernación holandesa lomos y puntas piel roja, tamaño en $4^{\circ}$. Son 78 volúmenes, numerados del 1 al 71 porque algunos están duplicados: $1^{\mathrm{BI}}, 35^{\mathrm{A}}, 35^{\mathrm{B}}$, $39^{\mathrm{A}}, 39^{\mathrm{B}}, 40^{\mathrm{A}}, 40^{\mathrm{B}}, 41^{\mathrm{BIS}}, 45^{1^{\circ}}, 45^{2^{\circ}}, 56^{\mathrm{BIS}}$. En total suman 1.029 títulos.

- Colección de Papeles varios impresos y manuscritos en folio. Se trata de 34 volúmenes numerados del 1 al 30 (también hay un $1^{\mathrm{A}}, 1^{\mathrm{B}}, 1^{\mathrm{C}}$, y $22^{\mathrm{BIS}}$ ) $\mathrm{y}$ guardan 557 títulos.

La duplicidad de los números de los tomos no parece tener una explicación evidente ni por la encuadernación (es bastante uniforme, sin diferencias significativas que hagan pensar que fueron encuadernados en diferentes fechas) ni por contenido, porque desde luego no son posteriores cronológicamente a los numerados de forma corrida. Como puede verse, faltarían los inventarios correspondientes a los tomos de Papeles Varios manuscritos e impresos, las monografías y también el de los Apuntes.

Si nos fijamos en su contenido, en ellos se describe cada volumen título a título, recogiendo en siete campos, distribuidos en otras tantas columnas, los siguientes datos: obra (título), autor, págs., lugar, imprenta, año y observaciones. Este último campo es muy variado, lo mismo recoge noticias sobre los grabados o las ilustraciones que contiene el ejemplar que indica que lleva notas marginales de Gestoso o cualquier otra curiosidad. La letra parece que es la de María si la cotejamos con las notas firmadas que se reparten por todo el legado de Gestoso. De ser así, estaríamos ante los inventarios originales, pero entonces ¿por qué no están firmados? ¿o cuántas copias se hicieron? Por otro lado, no cabe duda que el paralelismo de esta descripción con la de los inventarios mecanografiados hace pensar que estos manuscritos fueron los utilizados por el ayudante de la Capitular Colombina que los pasó a máquina. Esta conclusión se apoya en el texto de las portadas de los mecanografiados donde se dice expresamente que se trata de índices de los libros entregados a esta Biblioteca. El primero de ellos es el más extenso porque añade, en la primera hoja del texto, otro título similar aunque algo más amplio. Por su interés lo transcribo completo:

“Índice de los libros entregados a esta Biblioteca por la Excma. Sra. D ${ }^{a}$ María Daguerre D’hospital, viuda de Gestoso en cumplimiento de la cláusula séptima del testamento del Excmo. Sr. D. José Gestoso y Pérez por la cual dona sus libros a la Biblioteca Capitular Colombina de Sevilla. Cuaderno $\left(1^{\circ}\right)$ Junio de 1919".

“Entrega que hacer al Excmo. Cabildo Eclesiástico la señora D ${ }^{a}$ María Daguerre-Dospital y Buisson, viuda y albacea del Excmo. señor D. José Gestoso y 
Pérez, de acuerdo con los señores testamentarios el Ilmo. Sr. Dr. D. Modesto Abín y Pinedo, canónigo de la S.I.C., el señor Dr. D. Juan Villagrán y Gutiérrez y el señor D. José de Valdenebro y Cisneros, de la colección de volúmenes de Papeles Varios que componen la =Biblioteca $=$ de su expresado difunto esposo que los legó a la Capitular llamada $=$ Colombina $=$ por la cláusula séptima de su testamento otorgado ante el notario público D. Diego Angulo y Laguna, el día 10 de diciembre de 1912".

Este primer inventario contiene la descripción de los Papeles Varios manuscritos e impresos. Los siguientes simplemente llevan un título en portada similar al primero, indicando el número de cuaderno de inventario de que se trata y la fecha presumiblemente de entrega:

- Cuaderno $\left(2^{\circ}\right) 19$ de Marzo de 1920. Recoge las monografías.

- Cuaderno $\left(3^{\circ}\right)$ Agosto del año de 1920. Contiene la descripción de los Papeles Varios impresos en tamaño $4^{\circ}$.

- Cuaderno (4 $\left.4^{a}\right)$ Diciembre de 1921. Papeles Varios impresos en tamaño folio.

- Cuaderno $\left(5^{\circ}\right)$. Sin fechar, corresponde a Papeles Varios impresos en tamaño $8^{\circ}$.

Recientemente se han elaborado algunos instrumentos de descripción guiados por un criterio de eficacia y de complementariedad de lo ya existente. Veámoslos:

- Papeles Varios impresos (en tamaño $8^{\circ}, 4^{\circ}$ y $2^{\circ}$ ): se han transcrito los inventarios mecanografiados y se han cotejado con las obras originales para uniformar apellidos y términos, corregir errores, etc. ${ }^{22}$

- Papeles Varios de manuscritos e impresos: también se ha transcrito el inventario mecanografiado pero sin cotejo posterior con los originales debido a la escueta descripción de que adolece en este caso el inventario de María Daguerre y porque, además, cuentan con otros dos medios de información:

- Un fichero manual topográfico de los 41 tomos. Tras el separador que indica el ordinal de cada tomo podemos encontrar, en fichas individuales, una descripción de cada documento u obra. Se desconoce quién lo ejecutó y cuándo, aunque fue elaborado en fichas de la propia Biblioteca.

- Un catálogo de toda la colección obra de Pedro Cómez Ramos titulado "Catálogo de los tomos de manuscritos (Papeles Varios) del fondo documental José Gestoso existentes en la Biblioteca Capitular-Colombina de Sevilla. Memoria de Licenciatura inédita, 1975. Tras un estudio sobre Gestoso y esta parte de su legado en concreto, en la que incluye una de las más completas relaciones de las publicaciones del Licenciado, describe el contenido de los 41 tomos por bloques temáticos:

22 Se ha detectado las faltas de los tomos 5 y 13 de los Papeles Varios impresos en $4^{\circ}$. 
manuscritos, impresos, prensa, grabados y fotografías, etc., terminando con un breve índice cronológico y otro mucho más extenso onomástico y de materias.

- Monografías: Respecto a las que llegaron tras 1917, se ha procedido como en los casos anteriores: transcripción del inventario mecanografiado y su cotejo con las obras originales. Pero desde un principio Gestoso comenzó a donar ejemplares de sus propias publicaciones a la Biblioteca además de numerosos títulos de otros muchos autores, y para conocer las donaciones hechas en vida contamos con las siguientes fuentes:

- Noticias extractadas de su Correspondencia y de la conservada en el Archivo de la Catedral, sobre todo cartas de agradecimiento del bibliotecario de la Capitular o en algún caso de su oficial, Simón de la Rosa, y algunas del propio Gestoso. A través de ellas sabemos que entregó ejemplares de la $1^{\mathrm{a}}$ y $2^{\mathrm{a}}$ edición de su Guía artística de Sevilla en 1886; en 1889 la necrológica sobre Francisco María Tubino, su discurso en la Junta General pública de la Academia de Bellas Artes de 1888 y los folletos sobre La batalla de Bailén y Valdés y Mañara. Y así podríamos seguir durante años: El navío El Santo Rey San Fernando (1890); los tres tomos de Sevilla Monumental y Artística (1889, 1892 y 1901); Los Reyes Católicos en Sevilla (1891); Las Glorias Sevillanas de Manuel Serrano con la "Contestación" de Gestoso, seguido de nuevo de las Tradiciones Sevillanas de Serrano y el Segundo bodoque... de Gestoso (1895); la necrológica de Fernando Belmonte y Nuevos datos para ilustrar las biografías del maestro Juan de Malara y de Mateo Alemán (1896); los discursos de ingreso en Buenas Letras de Fernández López y su contestación de Gestoso; el Diccionario de artífices (T. I) y el folleto sobre Cristóbal de Morales (1901). ${ }^{23}$

- Libro copiador de comunicaciones de la Biblioteca Capitular (con datos de donaciones fechadas entre 1885-1902).

- Libro registro de entrada de la Biblioteca (que recoge las realizadas entre 1915 y 1941, si incluimos las que también hicieron su viuda y su hija). ${ }^{24}$

- Los ya mencionados listados de las donaciones de 1901 y 1904. Como sólo constan en ellos el autor, título y número de volúmenes, sin más datos ni particularidades, no procedía en este caso su cotejo con los originales, los cuales además no podemos asegurar que sean los localizados en la Biblioteca por carecer de marcas externas de procedencia.

- Correspondencia: Los tomos carecen de índice alguno, simplemente están encuadernados por orden cronológico con un contenido muy variable,

23 B.C.C., F.G., Correspondencia Tomo 2 de Cartas Curiosas n ${ }^{\circ}$ 57; 1889-90 n ${ }^{\circ}$ 29, 101, 210, 223, 248; 1891-92 n 78,233 ; 1895-98 no 8, 92, 152, 330; 1899-1900 n $114,1901-1902$ n 21.

24 B.C.C., sign. prov.: Caja 2, Libro Copiador de Comunicaciones y Registro de entrada de libros. 
ya que un solo tomo puede incluir varios años (1895-1898), uno solo (1916) o medio año ( $1^{\circ}$ 1909). Por ello ha sido necesario elaborar unos listados de contenido de cada volumen indicando el número de orden de cada carta, su fecha y remitente. La fecha en este caso puede resultar de utilidad porque en algunas ocasiones están mal encuadernadas y no se comprende su contenido si no se las lee en el orden correcto.

- Autógrafos: Están organizados alfabéticamente y todos los documentos correspondientes a cada letra están numerados y dentro de una carpetilla en la que hay un listado manuscrito de los nombres que contiene, completado en los años 80 del pasado siglo, cuando se le añadió además la numeración corrida. Actualmente se ha hecho un listado general del contenido de los cuatro legajos con los siguientes campos: letra, $\mathrm{n}^{\mathrm{o}}$ de orden, remitente/autor/imagen (ya que a veces es simplemente una fotografía o un dibujo) y destinatario. Se ha respetado la ordenación encontrada de los documentos, aunque alguno de ellos claramente debiera aparecer bajo otra letra.

- Apuntes: Estos tomos sin duda son los que ofrecían mayor complejidad para poder facilitar información de su contenido, ya que no se han conservado los inventarios originales. Los documentos de cada tomo suelen estar identificados por un número correlativo que lo mismo se refiere a un único documento o a un grupo de ellos relacionados entre sí. Por ello, y aunque evidentemente no sirve más que como un acercamiento, se ha elaborado un listado que recoge los títulos de los documentos o textos, en el caso de tenerlos, guiado -cuando lo hay- por el índice del tomo, o dando una definición genérica del contenido. Se ha añadido la referencia a la hoja de comienzo de cada título para facilitar su acceso.

- Títulos honoríficos: cuentan con un completo índice cada uno de los tomos, por lo que no ha parecido necesario añadir por ahora ningún medio más de información.

- Memorias De historia sevillana. Páginas de mi vida: en el anexo 3 se recoge el índice de los dos tomos, basado en el que contienen los originales pero completado con partes no identificadas en él. Al igual que en los Apuntes, se indica el número de hoja de inicio de cada uno de estos temas. La numeración original ofrecía saltos que dificultaba la localización de cada tema, por lo que se ha procedido a su foliación corrida a lápiz, que es la que consta, y se difunde por primera vez, en el índice adjunto.

Por ahora no se va a abordar la catalogación documento a documento de los tomos de Papeles Varios, sobre todo de los manuscritos, de la Correspondencia o de los Apuntes, pero sí se irán catalogando los folletos impresos y las monografías, algunas de ellas ya consultables en la base de datos de la Biblioteca. 
Además de los inventarios, se cuenta, tal vez desde 1923, con fichas manuscritas de todo el Fondo Gestoso, incluido el legado abierto en 1980, pero han pasado desapercibidas porque están insertas en el fichero general de la Biblioteca, tanto de autores como de materias y, salvo excepciones, no indican en ellas su procedencia, por lo que la simple lectura de la ficha no permite saber si corresponde o no a una obra del Fondo Gestoso. Las que sí lo mencionan llevan un característico rótulo en tinta roja en la esquina superior izquierda que dice así: Colción Gestoso, sobre todo en las fichas correspondientes a manuscritos. Otras consignan, además, la materia del libro en la esquina superior derecha, también en tinta roja. Algunas de estas obras sí están recogidas en el fichero con letra de otra mano pero las demás no lo están, por lo que es difícil entender por qué algunas fichas se han conservado aparte, sin colocar en su casillero correspondiente.

Por último, hagamos una breve mención al actual proceso de digitalización. Para facilitar la consulta tanto de los medios de información como de algunos originales del Fondo Gestoso, en la Biblioteca se han digitalizado todos los inventarios y listados originales conservados, tanto los mecanografiados como los manuscritos, y pueden ser consultados en las terminales de la Sala de Lectura, al igual que los inventarios y listados actuales, también disponibles en copia en papel. El que éstos últimos puedan verse en las terminales permite al investigador hacer búsquedas de términos, lo que facilita su consulta, que es imposible en la copia en papel o en las imágenes de los originales. En algún caso concreto se han digitalizado obras completas, pero en general se ha optado por los índices que contienen los tomos de Papeles Varios. Hasta ahora se han reproducido los siguientes, entre los que no se incluyen los documentos sueltos que se han digitalizado por algún motivo de cualquiera de los formatos misceláneos, sobre todo Autógrafos, Correspondencia y Papeles Varios impresos y manuscritos:

1. Los índices de los pocos tomos de Papeles Varios manuscritos e impresos que sí lo tienen, 14 del total de 41 volúmenes. No se ha hecho con los de los Apuntes porque ya aparecen transcritos en el listado actual de contenido de todos ellos.

2. El tomo II completo de esos Papeles Varios por estar compuesto todo él de artículos de José Gestoso.

3. Precisamente por tratarse de un texto manuscrito e inédito de Gestoso, se han digitalizado los dos tomos de sus memorias: De historia sevillana. Páginas de mi vida.

4. De los Autógrafos, el cuadernillo con noticias sobre documentos del Archivo de Protocolos conservado en el cuarto legajo y titulado: «Notas de escrituras curiosas entresacadas de los Índices y legajos del Archivo General de Protocolos por José Gestoso y Perez», fechado en Sevilla, 29 de agosto de 1914.

5. Índices de los tres tomos de Títulos honoríficos.

6. Por último, se ha procedido a la digitalización de obras de Gestoso aplicando un doble criterio: que trataran específicamente sobre la Catedral 
y la Biblioteca y que no se encontraran en repositorios digitales de acceso libre. En función de esto, se han reproducido, aparte del ya mencionado Tomo II, folletos como por ejemplo los dedicados a la sacristía mayor, la Virgen de los Reyes o la requisa de cuadros de la Catedral y títulos inéditos como:

- Blanca (Leyenda). Manuscrito, [1865]. En: Apuntes T. 1, no 5: 25-41 y no 8: 85-88 y 176-187.

- Manuscrito original de la Apología sobre las Novelas Ejemplares de Cervantes presentada a la Real Academia Sevillana de Buenas Letras con motivo de las fiestas que celebró esta Corporación para conmemorar el aniversario de la muerte del insigne autor del día 23 de abril de 1877 por J.G.P. Las correcciones son autógrafas de mi docto amigo y maestro el Sr. Dr. Dn. Juan José Bueno y Le-Roux. En: PP.VV.T. I, n 22, 243.

- Influjo e intervención de Diego de Riaño en la arquitectura sevillana del siglo XVI. Discurso de recepción en la Real Academia Sevillana de Buenas Letras. Borrador manuscrito, 1886. En: PP.VV. T. III nº 4: 46.

- Historia de los barros vidriados sevillanos. Manuscrito original, 2 tomos, 1901. Signatura actual: 76-4-4/5.

- Proyecto de ley que redactó con Adolfo Rodríguez Jurado sobre la creación de los Archivos Históricos Provinciales (mecanografiado) [1914]. Inserto en el T. I de sus Memorias, pp. 379-383.

Para facilitar la consulta de la bibliografía completa de Gestoso se ha elaborado un listado de todas sus obras conocidas indicando en él dónde puede consultarse en formato digital, tanto en repositorios externos como en la propia Biblioteca Capitular Colombina. Lógicamente este apartado de digitalización del Fondo Gestoso no puede darse por cerrado ya que a él se irán incorporando paulatinamente todas aquellas obras y documentos que por un motivo $u$ otro vayan siendo digitalizados.

\subsection{Contenido del Fondo Gestoso}

Entremos ahora en el apartado tal vez más complejo de todos: sintetizar el contenido del legado de Gestoso. Aunque a primera vista extrañe, no es tarea fácil. Como es lógico, cada una de las agrupaciones de volúmenes que hemos visto aporta una información en principio diferente pero no es exclusiva, ya que en muchos casos puede ser complementaria y en otros incluso se repite. Veámoslo por partes, comenzando por los impresos.

Los tomos de Papeles Varios impresos contienen obras en su mayoría coetáneas de Gestoso, de las cuales muchas fueron donadas por sus autores por tratarse de amigos o al menos conocidos del Licenciado. Las materias son muy diversas, aunque en su mayoría reflejan claramente las actividades que desarrolló 
toda su vida: Historia, Arte, Arqueología, Cerámica, Literatura, etc. Son también numerosos los discursos de ingreso en Academias y curiosa la amplia relación de obras impresas por Hidalgo en Sevilla, obviamente debido a la compra que hizo Gestoso del fondo que quedó tras el cierre de esta imprenta, incluso el tomo 32 de Papeles Varios en $4^{\circ}$ está dedicado a borradores para la imprenta. La fecha más moderna localizada en los tamaños $4^{\circ}$ y $8^{\circ}$ es 1916 y 1914 en los tomos de tamaño folio, lo cual no significa, como ya hemos visto, que todos ellos estuvieran encuadernados antes de la muerte de Gestoso. Respecto a la primera mitad del s. XIX, llama la atención la abundancia de impresos relacionados con la invasión francesa. En los tomos en $8^{\circ}$ hay algunas obras en torno a la masonería y otras rotuladas como prohibidas. También podemos encontrar títulos de siglos anteriores y la temática es absolutamente variopinta. En los más antiguos sobre todo temas literarios, religiosos y políticos y los coetáneos a Gestoso más relacionados con las actividades del Licenciado.

Es llamativo que estos tomos no se dedicaran exclusivamente a obras de Gestoso sino que haya títulos de otros miembros de su familia. Probablemente los de temas culinarios, fechados casi todos en las primeras décadas del XIX, procedieran de sus abuelos - $\mathrm{O}$ al menos de uno de ellos- por dedicarse uno a la repostería y otro a la fabricación de chocolate. Otros debieron pertenecer a su padre, por su fecha y temática. Hay incluso alguno del padre de María, de ella misma y de sus hijas. No deja de ser extraño que ellas se desembarazaran de estos ejemplares, y más en el caso de los que eran simples prospectos o catálogos de belleza, ${ }^{25}$ o el libro que Gertrudis Segovia le dedicó cariñosamente a sus cuatro hijas:"A mis queridas amigas Paz, Salud, Eugenia y Josefina Gestoso. ¡Qué mucho que a vosotras que sois el encanto mismo, vayan a buscaros estos encantamientos!... Sirvan estas modestas páginas para llevaros una vez más la expresión de mi constante y cariñoso recuerdo Gertrudis Segovia". ${ }^{26}$ Y ya que menciono una dedicatoria, conviene reseñar que esta costumbre es una buena, curiosa e incluso rica fuente de información sobre los amigos y conocidos de Gestoso.

En síntesis podríamos decir que se trata de una biblioteca fundamentalmente de trabajo, por lo que fueron títulos no sólo leídos por Gestoso sino también, en ocasiones, anotados por él al margen. Incluso cuando falta la portada del folleto, la hace él mismo. Esto no es óbice para que incluyera, como coleccionista que era, títulos heredados o curiosos de cualquier época y contenido. Aunque son tomos en su inmensa mayoría de impresos, podemos encontrarnos en algunos casos con manuscritos.

Prácticamente todo lo dicho hasta aquí sobre los folletos impresos es aplicable a las monografías que donó a la Biblioteca, salvo la presencia de obras de María o sus hijas. Respecto al contenido, una pequeña precisión: si leemos los

25 B.C.C., F.G., PP.VV. $4^{\circ}$ T. 69 n 14 y T. $71, \mathrm{n}^{\circ} 9$.

26 B.C.C., F.G., PP.VV. $8^{\circ}$, T. $33, n^{\circ} 3$. 
listados de las donaciones de 1901 y 1904 veremos que en gran medida se trata de Literatura, obras francesas y autores del XVIII y primera mitad del XIX o al menos de una generación anterior a Gestoso, mientras que los títulos del legado de 1917 son mucho más actuales, lo que abunda en la impresión de que la biblioteca que conservó y manejó era ante todo de consulta.

Siguiendo con las monografías, Gestoso llegó a donar en total alrededor de 700 y en ellas encontramos casi todos sus títulos. A modo de ejemplo, veamos algunos datos relacionados con las obras entregadas tras 1917: la inmensa mayoría son impresos, aunque hay algunos manuscritos, a veces tan curiosos como el ejemplar más antiguo de toda esta sección, un documento de Juan II fechado en 1420 (signatura actual: 78-4-3); los títulos de las casas de Juan Martínez Montañés (1483, 1602 y 1611) (signatura actual: 77-4-2) o la"ejecutoria y genealogía de la familia Dávila-Aguirre y certificación de nobleza de la familia Bécquer", fechada en 1633 (signatura actual: 78-4-9). Irá en progresión el aumento de títulos conforme avanzan los siglos. Así, son dos los fechados en el s. XVI, ocho en el XVII, veintisiete las monografías del XVIII, cuarenta y ocho las correspondientes a 1800-1850 y ciento dieciocho entre 1851 y 1899. La cifra del s. XX es significativa teniendo en cuenta que abarca sólo diecisiete años: 40 títulos. $^{27}$

Los tomos misceláneos más conocidos son los encuadernados en pergamino y que hemos definido como Papeles Varios manuscritos e impresos. Su contenido es tan diverso que es imposible sintetizarlo en unas líneas, porque podemos encontrar desde un documento del siglo XIII hasta una esquela de principios del siglo $X X$, dibujos y fotografías, artículos en prensa o pleitos del s. XVII. Así ocurre al menos con veinticinco de ellos. Los dieciséis restantes corresponden a volúmenes que giran en torno a un tema, a veces muy general y otras bastante específico, que sintetizo a continuación partiendo de lo indicado en la propia encuadernación:

- Genealógicos todo: tomos XIII y XIV

- Artífices: tomos XVII, XXII al XXIV, XXVI y XXXI

- Cartuja: Tomo XVIII

- Colegio de Santo Tomás: Tomo XXIX

- San Salvador: Tomo XXXIII

- Autógrafos: Tomos XXXVII al XLI.

A título de curiosidad, si seguimos las fechas que aparecen en sus portadas, Gestoso comenzó a preparar estos volúmenes, y tal vez a encuadernarlos, desde diciembre de 1884, según el tomo II, hasta 1916, fecha del t. XLI y último. En 11 de ellos falta este dato y en los que consta se suceden cronológicamente salvo

27 La suma de estas cantidades no alcanza el total de volúmenes, ya que varios títulos tienen varios tomos y algunos carecen de fecha. 
en un par de casos en que la fecha es muy posterior o muy anterior a la que le correspondería. ${ }^{28}$ Hay además saltos llamativos entre unos y otros, como por ejemplo de 1886 a 1896 o de 1906 a 1911. Hay años que no aparecen y otros en los que preparó varios tomos, como 1896 (3), 1900 (7) o 1916 (3).

Ya que hablamos de las portadas, conviene reseñar que, en su mayoría, son un verdadero muestrario de la habilidad de Gestoso como dibujante. Se suceden orlas, cenefas, guirnaldas, motivos arquitectónicos, heráldicos, diseños

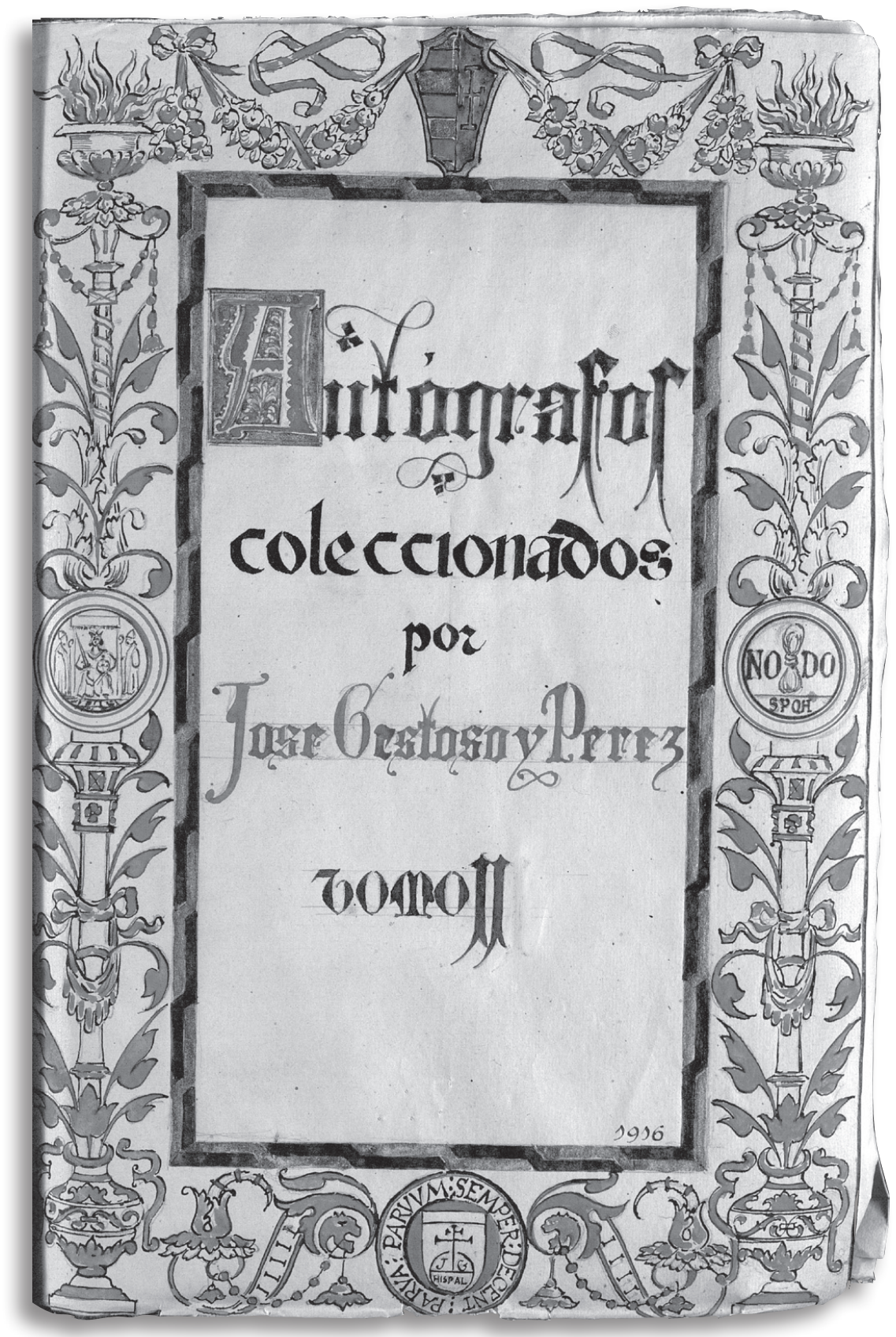

Figura 8. Portada del T. XXXVIII de los Papeles Varios. (C) Cabildo Catedral de Sevilla.

28 Se trata del T. XVI, fechado en 1906 pero está entre tomos de 1899 y 1900. El caso contrario es el T. XXXVII, de 1899, aunque las fechas del anterior y el posterior son 1914 y 1916 respectivamente. 
decorativos, los hay de estilo gótico, renacentista, mudéjar, regionalista... que unen la perfección del dibujo a la belleza de su colorido. Por algún -y desconocido- motivo (¿tal vez sean borradores?), muchas de estas portadas están duplicadas e incluso triplicadas y hoy se conservan en la familia. En algunas de ellas añade, junto a la fecha, el lugar en que los realizó. El más frecuente es Sevilla, pero también aparecen Alcalá de Guadaíra y Mondáriz, lugares de reposo muy a propósito para disponer del tiempo necesario para este tipo de tarea. El total de documentos numerados (a veces uno solo y otras un verdadero y variopinto conglomerado de decenas de ellos), es de 794, lo que hace una media de unos 49 por tomo. En la realidad, oscilan entre los 8 y los 184 . Son tomos muy gruesos, con una media de 455 folios cada uno (entre 309 y 573 los más gruesos), lo que hace un total de 18.657 hojas.

La Correspondencia es una impresionante fuente de información aún muy desconocida. Las más de 6.000 cartas que contienen los 23 tomos donados contienen las firmas más importantes del ámbito cultural en que se movía Gestoso, tanto de Sevilla como de toda España y de diversos países. También, aunque son casos excepcionales, incluye copias de cartas que él enviaba junto a la consulta -o respuesta- de su corresponsal. En cuanto al formato, podemos encontrar también tarjetas postales y de visita y, en algún caso, fotografías relacionadas con la correspondencia. Al llevar un orden exclusivamente cronológico se suceden en cada tomo los más diversos remitentes, salvo un caso, el último, dedicado exclusivamente a Adolfo Fernández Casanova y abarca desde 1882 hasta 1915, aunque también hay cartas suyas en la correspondencia general.

Estos tomos y los legajos con Autógrafos formaron el grueso de la donación que Gestoso quiso que estuviera clausurada hasta 1980, según sus palabras, a fin de que por lo pronto no tengan los chismosos, aficionados al conocimiento de intimidades personales, motivos de entretenimiento. ${ }^{29}$ Una precisión: no todas las cartas del Fondo Gestoso están reunidas en estos tomos, algunas las incorporó a su colección de Autógrafos, aunque fueran remitentes habituales como Luis Montoto por ejemplo, y otras las unió a los asuntos de los que trataban, como podemos comprobar en el apartado que dedica en sus Memorias a la corona de la Virgen de los Reyes, donde incluyó cartas de agradecimiento por el folleto que publicó sobre este asunto. Incluso en ocasiones inserta o pega a algún libro la carta que le envió su autor donándoselo.

Los mencionados Autógrafos, un total de 1.136 documentos, se conservan en cuatro legajos en tamaño $4^{\circ}$ organizados alfabéticamente. Todos los de cada letra están numerados sin seguir un estricto orden alfabético y dentro de una carpetilla en la cual se relacionan todos ellos con su número correspondiente. La distribución es la siguiente: Legajo 1: Letras A-CH; leg. $2^{\circ} \mathrm{D}-\mathrm{K} ; 3^{\circ} \mathrm{L}-\mathrm{Q}$ y $4^{\circ} \mathrm{R}-\mathrm{Z}$. En el primero hay además al principio cinco catálogos de exposiciones de pintura

$29 \quad$ A.C.S., Fondo Capitular, Sec. I, Correspondencia leg.11.191 expte. 17. 
española, todas ellas organizadas por José Pinelo entre 1909 y 1914 en Buenos Aires, Rio de Janeiro y Sao Paulo. En el cuarto y último legajo se conserva el ya mencionado y curiosísimo cuadernillo manuscrito de Gestoso sobre documentos del Archivo de Protocolos hispalense. Debido a su mal estado, se han sustituido las hojas de guarda de los legajos y las cintas, pero se han conservado las carpetas de cartón exteriores y las carpetillas en papel que agrupan los autógrafos de cada letra.

Respecto a su contenido, no puede ser más heterogéneo, tanto por la tipología de los documentos, entre las que encontramos cartas, tarjetas, fotografías, breves autobiografías, etc., como por sus fechas. La mayoría proceden de personajes coetáneos de Gestoso, pero también podemos encontrar nombres de la primera mitad del s. XIX. Aquellos en los que el destinatario es el propio Gestoso bien podrían haberse incluido en sus tomos de Correspondencia, pero los demás se encuadran claramente en su faceta de coleccionista y muchos le fueron facilitados por sus amigos.

Los dos siguientes tomos fueron también legados bajo la condición de que no se permitiera su consulta hasta 1980 . Se trata de las tan mencionadas Memorias tituladas De historia sevillana. Páginas de mi vida. La importancia que Gestoso atribuyó a esta obra queda reflejada en su propia encuadernación, en pergamino con su escudete gofrado en oro y cierres y botones de badana, y en que estaban custodiadas en la ya mencionada caja de nogal a medida. ${ }^{30}$

Los llamados Apuntes son 16 tomos en $4^{\circ}$ que contienen, una vez más, la más variada información. Hay 14 tomos numerados correlativamente que son los que coinciden con la cantidad que entregó María Daguerre en 1923, pero hay otros dos con numeración romana de los que se desconoce cuándo fueron entregados, aunque desde luego no fue en vida de Gestoso, ya que el tomo II (h. 264) contiene un recorte de prensa de 30 de septiembre de 1917 y, además, el sello del encuadernador corresponde ya a los hijos de Márquez, es decir, que se encuadernó a partir de 1920. En estos volúmenes lo más frecuente es encontrar, como su propio título hace suponer, notas tomadas por Gestoso, muchas de las cuales le sirvieron después para sus publicaciones como él mismo indica. Así, por ejemplo, en el tomo 3, dirá al comienzo: la mayor parte de estos Apuntes tomados por mí en el Archivo del Alcázar han sido publicados en el tomo primero de mi obra Sevilla monumental y artística que acabo de imprimir en Enero de 1889.

Son misceláneas realmente interesantes porque recogen todo lo que Gestoso ve, anota o comenta, muchas veces acompañado de fotografías o dibujos. En ocasiones el texto se convierte en un diario en el que consigna tanto lo que va haciendo como noticias relacionadas con Sevilla, aderezadas en ocasiones con juicios personales, a veces realmente jugosos. Como ocurre con los Papeles Varios manuscritos e impresos, el contenido de la mayoría de estos tomos es muy

30 Sobre esta Memorias ver mi estudio en José Gestoso y Sevilla..., sobre todo la p. 235 y ss. 
variado, salvo algunos en los que sí reunió Gestoso datos de un mismo asunto, como los tomos 3 y 10, monográficos sobre el Alcázar; el 5, donde encuadernó las noticias que extractó del Archivo de la Catedral, o los tomos 7 y 8, dedicados a este templo. Por su parte, el tomo 11 contiene los Apuntes ya utilizados en los tomos $1^{\circ}$ y $2^{\circ}$ de Sevilla monumental. La fecha de estos tomos, según las portadas, se extiende desde $1885 \mathrm{el} \mathrm{tomo} 1^{\circ}$ hasta $1914 \mathrm{el} 14^{\circ}$, pero en realidad contienen

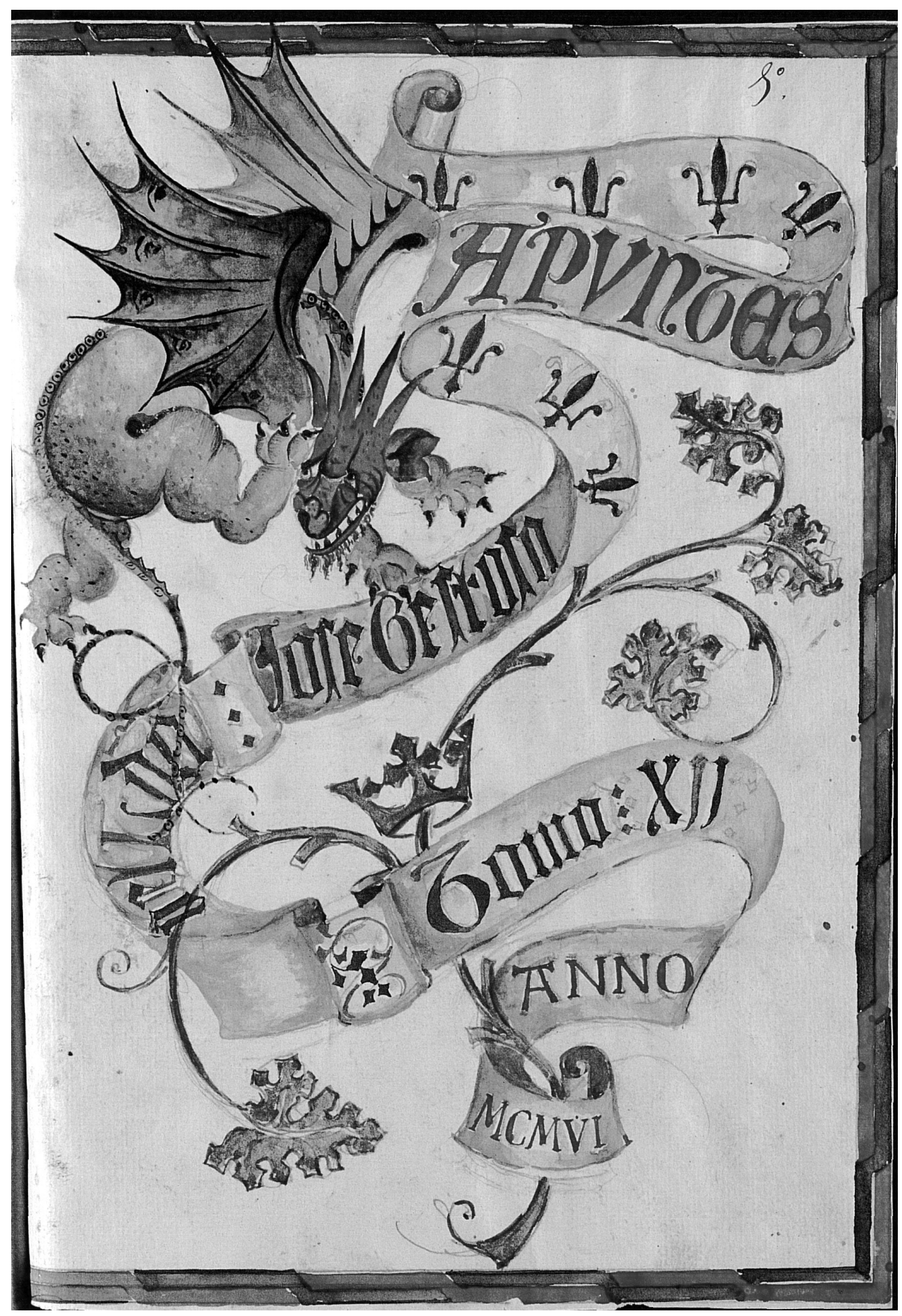

Figura 9. Portada del Tomo XII de los Apuntes de Gestoso. (C) Cabildo Catedral de Sevilla. 
algunos documentos antiguos, incluso del siglo XVII, apuntes de fechas anteriores a las consignadas en las portadas o el caso contrario, documentos sensiblemente posteriores a la fecha indicada. Por ejemplo, el tomo 1 contiene una fotografía de 1901; el t. 4, fechado en 1889, tiene noticias de 1913; el t. 6, de 1890, llega hasta 1911 y el 7º de 1891, a 1914. En otras ocasiones, las menos, el año de portada coincide con la fecha más tardía de los documentos de ese volumen. La presentación es menos cuidada que la de los Papeles Varios encuadernados en pergamino pero aún así algunos de ellos tienen bonitas portadas decoradas, como las de los tomos 7, 8, y del 10 al 13.

Cerremos este apartado mencionando los tres tomos sintetizados bajo el rótulo de Títulos honoríficos porque así aparecen en el libro registro de entrada de la Biblioteca, aunque como ya se comentó, en realidad son sólo dos de ellos los que ostentan este título. El tercero recoge Méritos y Servicios relacionados con el Ayuntamiento. Contienen una interesante información sobre encargos, reconocimientos de trabajos, concesiones de premios, distinciones y agradecimientos. No los donó José Gestoso porque se entregaron en 1941 y debió hacerlo su hija Paz por ser suya la nota que hay en el tercero de ellos tras el índice. Es evidente la diferente encuadernación y, además, al final de cada tomo se incluye un útil índice mecanografiado que remite al número de cada uno de los documentos.

Todo lo hasta aquí descrito está accesible a los investigadores desde 1923 -la mayor parte- y el resto desde 1980. Sin embargo, es obvio su desconocimiento incluso dentro del entorno cultural sevillano y muy pocos historiadores, o investigadores de unas y otras materias, se han acercado a este legado, tal vez porque la falta de instrumentos de descripción (sólo estaban las fichas catalográficas del fichero manual), ha impedido tener una visión global de esta donación y, en el caso de tenerla, el hecho de requerir la búsqueda de cualquier dato la lectura a veces de tomos completos provocaba más un efecto disuasorio que atrayente. Por lo tanto, llegados a este punto, es el momento de hacer algunas indicaciones sobre cómo buscar en el Fondo Gestoso, y lo primero que conviene aclarar es si, efectivamente, hablamos de este legado en su conjunto o de noticias sobre Gestoso. En el primer caso nos referimos a cualquier obra, dato y/o autor contenidos en los tomos donados por el Licenciado a la Biblioteca, se refieran o no a él. En el segundo, si buscamos noticias sobre su figura, aparte de consultar su Fondo habría que acercarse a otras fuentes, tales como:

- El fichero general manuscrito de la Biblioteca.

- El catálogo informatizado de la Biblioteca Capitular Colombina, donde podemos encontrar noticias de ejemplares que no pertenecen al Fondo Gestoso pero sí a la Capitular: libros procedentes de otras donaciones pero dedicadas por el Licenciado a los donantes, o títulos de Gestoso que poseyeron éstos o fueron adquiridos por el Cabildo, ediciones facsimilares, etc. 
- La documentación conservada en el Archivo de la Catedral de Sevilla: actas capitulares y correspondencia principalmente pero también el fondo de la Junta de Obras de la catedral, en la que él intervino como secretario.

Aun ciñéndonos al primer caso, la búsqueda de cualquier asunto en todo el legado, debemos desglosar en dos grandes grupos las posibles opciones: si se trata de un tema concreto o de un personaje, aunque pueden solaparse en algún caso, es decir, que podamos encontrar un nombre precisamente dentro de un apartado dedicado a un tema, como ocurre con Pedro Domínguez y la restauración del Ayuntamiento (recogida en las Memorias de Gestoso) o al revés: encontraremos noticias sobre Adolfo de Castro, por ejemplo, en el apartado de esas Memorias dedicado a la Biblioteca Capitular Colombina.

Entendiendo por "tema" o "asunto" un hecho histórico o un objeto, la consulta debe hacerse a través de los medios de información que nos pueden facilitar datos de materias, por lo que en principio habría que descartar la Correspondencia y los Autógrafos, salvo que conozcamos algún nombre relacionado con el tema en cuestión. Por la amplitud del contenido que abarca, podría empezarse la búsqueda consultando el índice de las Memorias de Gestoso, continuando por los tomos de Papeles Varios de manuscritos e impresos y los Apuntes. Por último, no habría que descartar como posibles fuentes la colección de Títulos honoríficos y los impresos, tanto los Papeles Varios como las monografías.

Los medios de información ahora disponibles permiten acceder a estos apartados del Fondo Gestoso cada uno con sus propias características. Así, el índice de las Memorias remite exactamente al asunto objeto de la búsqueda; los distintos repertorios de acceso a los tomos de Papeles Varios manuscritos e impresos facilitan la consulta de muy diversas formas: fecha, materia, nombres propios, tipología documental, etc. El listado de contenido de los Apuntes es tal vez el más limitado pero al menos es el primero con que contamos para acceder a estos volúmenes. El completo índice de los Títulos honoríficos permite una búsqueda rápida y sencilla. En cuanto a las monografías y los Papeles Varios impresos, los inventarios realizados por María Daguerre Dospital son sin duda instrumentos de gran utilidad por la amplitud de datos que facilitan.

Si buscamos noticias de un personaje concreto, podemos encontrar datos, cartas o incluso obras suyas. En los dos primeros casos tendríamos que consultar los listados de la Correspondencia y los Autógrafos, sin olvidar que hay también tomos de autógrafos en los Papeles Varios manuscritos e impresos. Las obras las buscaríamos en los listados de los Papeles Varios impresos y de las monografías. Es posible también que haya alguna información en los tomos de Títulos honoríficos. El resto de las fuentes pueden sernos útiles si sabemos cuál fue la actividad que desarrolló, ya que es más sencillo encontrar por esta vía -las"materias" - datos en los Papeles Varios de manuscritos e impresos, los Apuntes o en las Memorias de Gestoso. 


\section{DATOS DE LA BIBLIOTECA Y EL ARCHIVO CAPITULARES EN EL FONDO GESTOSO}

Dentro de este legado podemos encontrar muchas noticias extraídas por Gestoso de los ricos fondos bibliógraficos y documentales capitulares. La huella de las investigaciones que durante prácticamente toda su vida llevó a cabo Gestoso en la Biblioteca Capitular Colombina -y en menor medida en el Archivo de la Catedral- ha quedado reflejada de muy diversas formas. Desde luego, gran parte de ellas quedaron de manifiesto en sus publicaciones, bien como simples citas de datos insertos en los textos o bien transcribiendo directamente los documentos. Es tan frecuente la cita de sus fondos, sobre todo de manuscritos de la Capitular, que resultaría imposible sintetizarlos en estas líneas, ni siquiera los mencionados sólo en su obra Sevilla Monumental y Artística. Para hacernos una idea me limitaré simplemente a indicar algunos de los apellidos más conocidos: Caro, Peraza, Cuesta y Saavedra, Gordillo, Ortiz de Zúñiga, Loaysa, Guadix, Muñiz, Báñez de Salcedo, Matute... Libros litúrgicos, historias y memorias de Sevilla, las cartas de Cean Bermúdez a San Martín, las crónicas castellanas, todo pasó por sus manos y de ellas a sus libros.

Por otro lado, los datos extraídos, el material en que fundamentó sus estudios, quedó recogido en su legado, volviendo así, al cabo de los años, al lugar de donde fueron extraídos. Siguiendo con la Biblioteca, podemos encontrar en el T. 7 de los Apuntes, h. 352-354, una lista que le facilitó el oficial Simón de la Rosa a Gestoso sobre Códices de la Capitular Colombina y que éste publicó en parte en Sevilla Monumental y Artística al hablar de la Biblioteca (T. II, p. 140-141). En este mismo volumen hay una relación sobre Libros consultados sobre Sevilla, la mayoría procedentes de la Capitular y con alguna mención a la Arzobispal (h. 283). En otros tomos podemos encontrar las más variadas noticias: "Libros de Coro de la Catedral de Sevilla por los Sres. D. Adolfo F. Casanova y D. Claudio Boutelou 1884" (T. 6, n 6, h.37); noticias peregrinas sacadas de manuscritos de la Biblioteca, como el nuevo estofado que se hizo a la Inmaculada Concepción de Martínez Montañés (la Cieguecita) en 1779 (T. 8, h. 37); la mención al primer inventario conocido de la Biblioteca, de 1522 (T. 1, h. 250); el Extracto de una obra manuscrita que se intitula: Apuntaciones que podrán servir para indicar el origen y establecimiento de imprentas en España, de Diego Alejandro de Gálvez, 1796 (T. 12, h. 173); una reproducción fotográfica del manuscrito de las Valencianas Lamentaciones (PP.VV., T. IV, h. 39); la correspondencia entre Antonio de San Martín y Antonio María Espinosa y Cárcel (sign.: 57-5-26bis); la copia que obtuvo de la impronta de los sellos de la Capilla Real recogidos en el manuscrito de Muñiz, mencionados incluso en Sevilla Monumental y Artística (T. II, p. 331), etc. etc. También dará noticias de manuscritos capitulares, por ejemplo, en su Historia de los barros vidriados sevillanos y en Valdés Leal. 
Ahora bien, aunque las noticias que habitualmente se publican sobre Gestoso y la Catedral se relacionan con la Biblioteca, su consulta del Archivo capitular también fue importante. Menor sin duda en el tiempo pero muy rica en cuanto a los datos obtenidos. Por ello, aunque este artículo se centre en su legado a la Colombina, creo necesario dedicar un apartado al Archivo, ya que está presente en muchas de sus obras y apuntes. Fue para Gestoso valiosísima fuente de información, sobre todo para el segundo tomo de Sevilla Monumental y Artística, dedicado íntegramente al templo hispalense, pero también lo vemos citado en otras obras suyas como las ya mencionadas Historia de los barros vidriados sevillanos y Valdés Leal.

La entrada como investigador de Gestoso en este fondo documental es claramente posterior a la Biblioteca y tiene fecha concreta: 1887. Antes, había ya hecho alguna consulta puntual como lo demuestran las citas que hace de actas capitulares, copiadas, como él mismo afirma, de los originales, ${ }^{31}$ pero sobre todo tenía un conocimiento de su contenido indirecto, bien a través de otros autores como Ortiz de Zúñiga y Cean Bermúdez, o de copias, como los extractos de autos capitulares que hizo Juan de Loaysa en el XVII, conservados en la colección del Conde del Águila en el Archivo Municipal, del que Gestoso fue auxiliar entre 1881 y 1885. A ellos remite en su Guía artística de Sevilla, estudio que él mismo calificó como previo o de ensayo para Sevilla Monumental y Artística. Sin embargo, debió considerar la necesidad de recurrir a las fuentes originales para trabajo de tal envergadura y así, en 28 de junio de 1887, solicitó el siguiente permiso al Cabildo, dirigiéndose a él como "profesor en la Academia de Bellas Artes". Comienza contando cómo el Ayuntamiento le ha encargado escribir una historia monumental y artística de la ciudad, para lo cual ha consultado archivos públicos y privados y, por ello,

No ha de ocultarse a V.E.Y. la necesidad en que se halla de acudir al Archivo de la Santa Iglesia Catedral, si ha de historiar dignamente la grandiosa fábrica de su templo, el mayor y más señalado testimonio de la piedad, ilustración y generoso desprendimiento de nuestros mayores, pudiendo así esclarecer los puntos dudosos $\mathrm{u}$ oscuros que al presente se ofrecen, dando a luz nombres que yacen olvidados de artífices y maestros eximios y poniendo de manifiesto, para enseñanza de los entendidos, el caudal de datos y noticias que el mencionado Archivo atesora. En su virtud el exponente.

Suplica a V.E.Y. se sirva de concederle su venia para examinar y tomar notas de los documentos, exclusivamente de interés histórico o artístico, que en aquel rico depósito se custodian, con lo cual, no sólo prestará al que suscribe señalada merced, sino que contribuirá con tan poderosa ayuda al buen éxito de su trabajo, a enaltecer las glorias del grandioso templo hispalense y dará elocuente muestra de su ilustración y amor a las inmortales tradiciones del arte cristiano. Sevilla 28 de Junio de 1887". ${ }^{32}$

31 Archivo Hispalense T. I (1886) p. 379 y T. II (1886), p. 6 y 12.

32 A.C.S., Fondo Capitular, Sec. I, leg. 11.175, nº 11. 
El asunto se tratará en el Cabildo del 1 de julio y se solicitará informe a los señores archivistas. El día 13, leído dicho informe, se acordó acceder y se accedió a la petición del Sr. Gestoso en los términos y con las condiciones que se proponen en el informe, pudiendo tener lugar el estudio y toma de notas los dias de labor durante las horas canónicas de la mañana, ante el Sr. Archivista. ${ }^{33}$ Desconocemos el informe citado y, por lo tanto, el plan de estudio en él propuesto, peor al menos nos ha llegado la versión de Gestoso sobre su acceso al Archivo capitular en sus Apuntes. Su relato merece ser copiado aquí:

Empezé mis investigaciones en el Archivo de la Sta. Iglesia el día 12 de Julio de 1887 = Zúñiga (tom. II pág. 292) dice: las cosas de esta Santa Yglesia de ninguno han sido tratadas con fundamento porque a todos se han dificultado los de la vista de sus instrumentos que permitidas a mi confianza debe ser en mí de igual reconocimiento". Por lo que respecta a los escritores modernos a ninguno se había permitido la entrada en el Archivo ni a los de esta ciudad ni a los de fuera. Todos mis esfuerzos a este fin fueron inútiles hasta que interesé al Emo. Cardenal González quien enérgicamente dispuso se me franquease la entrada. He encontrado sus papeles confusos y revueltos como los dejó el Canónigo Ochoa a propio intento creyendo salvar así los bienes del Cabildo cuando la desamortización del año (en blanco) He notado también falta considerable de documentos, planos y trazas de las obras, privilegios y cartas. ${ }^{34}$

Y en otro lugar añadirá, aunque con error en la fecha, porque no hay duda de que fue en julio,

El dia 11 de junio de 1887 entré a trabajar en el Archivo de la Catedral con el Sr. D. José Cañamache Canónigo Doctoral empezando en ese dia el arreglo que de sus papeles me propongo hacer. Encontré el primer libro de cuentas de la obra de la catedral existente el dia 5 de octubre y di la noticia de su hallazgo a 1 Sr. C. el jueves 6 por consiguiente he sido el primero en hallarlo por más que si él lo hubiera encontrado nada habría conseguido pues no sabe leer letra antigua y así todos los documentos que publica son copias de copias modernas..$^{35}$

Durante más de dos años consultó sistemáticamente los libros de actas capitulares, de Fábrica y Adventicios, además de los tres Libros Blancos ${ }^{36}$ y los privilegios rodados. Una vez comenzada la tarea, irá revisando los libros, uno a uno y por orden cronológico, partiendo desde finales de la Edad Media

\footnotetext{
A.C.S., Fondo Capitular, Sec. I, sign.: 07271, h. 35v y 38r.

B.C.C., F.G., Apuntes T. 5, 1.

35 B.C.C., F.G.,Apuntes T. 7, h. 376. Es claramente un error en el mes porque la carta de petición de acceso está fechada en 28 de junio.

36 Aparte de noticias en Sevilla Monumental y Artística, sobre estos libros ver: Apuntes T. 7, h. 380386 (fotografía). En Los Reyes Católicos en Sevilla (1477-78), publicado en 1891, menciona los tres Libros Blancos del Archivo de la Catedral, describiendo pormenorizadamente la inicial con la imagen de Isabel la Católica seguido de una transcripción del documento (pp. 26-30).
} 
hasta comienzos del siglo XVIII. En la mayoría de ellos fue registrando su consulta, poniendo notas como ésta en el interior de la cubierta posterior o en la inmediata hoja de guarda: Registr ${ }^{\circ}$ Obre. $88 \mathrm{JG}$. Esta costumbre, que no entro a calificar pero que no era desde luego exclusiva del Licenciado, ha permitido sin embargo que una revisión libro a libro de las Actas Capitulares y de los de Cargo y Data y Adventicios de Fábrica nos permita reconstruir sus consultas en el archivo casi con tanta fidelidad como si hubiera rellenado una papeleta de consulta. Aunque comenzó Gestoso en el mes de julio, la primera nota localizada es ya de septiembre de ese mismo año 1887, en el libro de Cargo y Data 09341. En general cada tipología refleja una sucesión bastante uniforme en las fechas, es decir, que Gestoso hizo una revisión por orden cronológico de todos los libros, si bien a veces consultaba a la vez libros de distintas series. Por ejemplo, en enero de 1889 revisó tanto libros de Adventicios como de Cargo y Data.

Es innecesario -y sería además enormemente extenso- entrar en detalles, baste decir que esta consulta sistemática se prolongará desde septiembre de 1887 hasta octubre de 1889, salvo algunos meses concretos en que no visitó el Archivo, como febrero y marzo de 1888 y de febrero a mayo de 1889, tal vez debido a que por entonces estaba publicando otros trabajos. Los libros de Cargo y Data los consultará entre el ya mencionado septiembre de 1887 y octubre de 1889, ${ }^{37}$ constando su última nota en el tomo 09540. Se dedicó a los libros de Adventicios desde enero de 1889 (libro 09597) hasta el mes de mayo (09710) y a las Actas Capitulares, al menos según sus notas, en 1888, aunque en estos casos no suele constar el mes.

Es evidente que, una vez más, Gestoso fue más allá del papel de investigador y dejándose llevar de sus propias inclinaciones, comenzó a organizar y explorar en otras dependencias de la Catedral donde encontró libros que faltaban en el Archivo, como él mismo anotó en el interior de la cubierta de un libro de Fábrica y uno de los muchos testimonios que de este tipo dejó a su paso por el Archivo: Encontré este libro en el arch(ivo) alto de Contaduría el día 25 de octubre de 1889 con otros de Adventicios y el de las cuentas de la biblioteca que lleva puesto en el lomo el epígrafe Librería 1677. JG. No será el único "descubrimiento" que haga en tal lugar, ${ }^{38}$ por lo que resulta sorprendente que en Sevilla Monumental y Artística (T. II, p. 371) llegue a decir esto de la estancia de la antigua Contaduría Alta: hoy convertida en archivo de Propios y Rentas, y cuya documentación en los conceptos histórico y artístico no ofrece el menor interés. Incluso rotulará algún libro, como el de Costas Generales del año de 1440. Este epígrafe lo he puesto yo en la cubierta de pergamino, el libro carece de él y solo en la segunda hoja se lee... ${ }^{39}$

37 Dato obtenido de sus notas en los libros y que coincide con la que recoge en el T. 7 de sus Apuntes, h. 175: Hoy 15 de octubre de 1889 he concluido de registrar los libros de Fábrica.

38 A.C.S., Fondo Capitular, Sec. IV, Fábrica, sign. 09336. De Adventicios: 09611, 09613 y 09615.

39 B.C.C., F.G., Apuntes T.5, h. 7. 
El resultado de sus investigaciones lo recogerá en sus tomos de Apuntes, en concreto $\operatorname{los} n^{\circ}$ 5, 7 y 8. El primero contiene, según la portada, Extracto de las Cuentas de la fábrica de la iglesia de Sevilla por José Gestoso y Pérez. 1887 (h. 3). A continuación los desglosa desde 1440 a 1598. En la última hoja, 341, dice Continúan los extractos de Libros de Fábrica en el Tom 7 de esta colección, como ahora veremos. El cotejo de los años que vio Gestoso con el listado actual de libros de Fábrica revela que prácticamente todos pasaron por sus manos, salvo muy contadas excepciones. Lo mismo podemos decir de las actas.

Los tomos 7 y 8 están dedicados a la Catedral, aunque en realidad el $7^{\circ}$ sea en buena parte continuación del tomo 5:

- $\quad N^{o} 1$ Extractos de Autos Capitulares desde 1478 a 1591 (h. 3-154)

- No 2 Id. de Libros de Fábrica desde 1601 a 1699 (h. 155-177). Véanse los anteriores, desde 1440 a 1598, en el tomo $5^{\circ}$ de mis Apuntes

- $\quad N^{o} 3$ Id. de los de Adventicios desde 1547 a 1601 (h. 178-238).

- A partir de aquí, el $n^{\circ} 4$ tendrá un contenido absolutamente diverso: "Catedral Noticias Varias 1891. Como reflejo de su meticulosidad, valga la siguiente nota recogida en la h. 244 tras la copia de un documento sobre Hernán Ruiz y Morel: Hallé este documento dentro del libro de Cargo y Data de 1565 y lo he dejado en el mismo sitio en la $6^{a}$ foja.

El tomo 8 sí está dedicado plenamente a Noticias de la Catedral de Sevilla y es tan rico y variopinto que no puedo entrar aquí en detalles porque se van sucediendo datos, inventarios, copias de documentos, etc. También en el tomo 4 podemos encontrar más noticias relacionadas con el templo, en concreto, copias de documentos (como los $n^{\circ}$ 2, 11, 12 y 13). Al menos en una ocasión, la localización de un documento le llevó a su publicar su transcripción en el Boletín Oficial del Arzobispado de Sevilla. Me refiero a los Documentos relativos a la Hermandad de Nuestra Señora del Pilar y Hospital Real de Sevilla, copiados por Don José Gestoso y Pérez, de un tomo de PP.VV. que coleccionó D. Juan de Loaysa (Arch. de la Cat.) (B.O.A.S. de 1888, pp. 550-558 y 596-606).

No quiero extenderme mucho más en este apartado, pero sí creo que merece la pena recoger aquí dos curiosas noticias relacionadas con el Archivo. En el curso de sus investigaciones, Gestoso encontró por primera vez, en un asiento del libro de Fábrica de Cargo y Data de 1558 sobre los gastos de la solería de la Biblioteca, una mención a azulejos de cuerda seca, consagrando a partir de entonces el uso de tal término para denominar esta técnica de decoración cerámica de origen musulmán. Publicó su descubrimiento en Historia de los barros vidriados sevillanos ( $\mathrm{p} 55$ ).

También en esta obra publicará la segunda noticia (pp. 69-70): En el año 1890, al remover el pavimento del oro de nuestra basílica, y como a un metro aproximadamente del nivel actual, al pie del segundo pilar del mismo Coro, descubrióse un trozo de solería de azulejos, formando mosaico, que medía en conjunto casi un metro 
cuadrado, incluyendo además un dibujo del hallazgo. Se conserva este original junto a otros tres en el Archivo de la Catedral. En el dibujo coloreado similar al publicado apenas se lee en la parte superior este título: Catedral de Sevilla. Mosaico encontrado en el Coro.

El Archivo General del Arzobispado también fue objeto de investigaciones y pesquisas aunque en menor medida y por ello no me detendré, pero sí quisiera mencionar una importante contribución de Gestoso: que promoviera el depósito en él del archivo del gremio de plateros. Gracias a esta iniciativa se ha preservado de la evidente pérdida a la que estaba destinado como otros muchos archivos de gremios. Él mismo lo cuenta en un artículo publicado en El Correo de Andalucía el 14 de marzo de 1914 que insertó en el Tomo I de sus Memorias, h. 304. Consultó también la Biblioteca Arzobispal, que citará en alguna ocasión y para la que no tendría sin duda dificultad alguna en acceder por ser por entonces su bibliotecario su buen amigo el presbístero José Alonso Morgado.

Por último, no podía quedar fuera de sus investigaciones el archivo de la Capilla Real, como quedó de manifiesto en Sevilla Monumental y Artística, obteniendo para ello el permiso del Arzobispo, según le comunica Servando Arbolí en 30 de marzo de 1889 en esta curiosa carta:

“está V. autorizado ya por su S. Emma. Para registrar los libros de actas de la Capilla real. En su virtud, podrá personarse en [nuestra] sala el lunes a las 9 de la mañana, y al propio tiempo debo decirle que puede exigir de quien corresponda la devolución de la propina que le interesaron días pasados, porque ya di orden expresa y terminante de que esperasen a V. de conformidad con lo que me indicó el Sr. Deán." ${ }^{40}$

Custodiado en el Archivo de la Catedral se encuentra el fondo de la Junta de Obras del templo, en la cual durante años tuvo un papel importante Gestoso por ocupar el cargo de Secretario. Por lo tanto, para conocer mejor su figura debe tenerse en cuenta la consulta este fondo. Precisamente su labor en esta Junta dejó una huella entre sus papeles y, así, podemos encontrarnos citas para reuniones, noticias de gastos, copias de actas, de proyectos e incluso un Inventario de la documentación que la suprimida Junta de Obras entrega al Arquitecto Director de las mismas en cumplimiento de la O. de la Dirección General de Obras Públicas fecha 9 de octubre de 1889. ${ }^{41}$

40 B.C.C., F.G., Correspondencia, 1889-1900, no 39 y Sevilla Monumental y Artística T. II, p. 333 y ss.

${ }^{41}$ Apuntes T. 7, h. 274, 310 y 402 y PP.VV.T. XVI nº 3, f. 4-11 y T. IV n 4, f. 40 y ss. 


\section{ANEXO 1: ESTUDIOS SOBRE EL FONDO GESTOSO}

Se recogen a continuación, sin afán de exhaustividad, algunos trabajos localizados en los que se incluye la edición y estudio de documentos de este legado. En primer lugar, el valioso estudio sobre la colección de Papeles Varios manuscritos e impresos, seguido por varios artículos clasificados según los documentos que transcriben:

CÓMEZ RAMOS, Pedro: Catálogo de los tomos de Manuscritos (Papeles Varios) del fondo documental José Gestoso existentes en la Biblioteca Capitular Colombina de Sevilla, Memoria de Licenciatura inédita. Sevilla, 1975.

Correspondencia:

CASQUETE DE PRADO SAGRERA, Nuria: El mausoleo de Colón ¿dónde debe colocarse? Una curiosa historia en la Sevilla de fines del XIX (1898-1902), en "Boletín de la Real Academia de Bellas Artes de Nuestra Señora de las Angustias", Granada, 14 (2007) 137-191.42

Papeles Varios manuscritos e impresos:

HERRERA GARCÍA, Francisco J.:

- Gaspar Becerra: su entorno familiar y profesional a la luz de nuevas fuentes documentales", en"Boletín Museo e Instituto "Camón Aznar»" XCIII (2004) 59-96.

-Flandes-Canarias, a través de los talleres sevillanos. Un encargo escultórico a Sevilla a comienzos del XVI, en“Homenaje a la profesora Constanza Negrín Delgado". Carlos Rodríguez Morales (ed.) Instituto de Estudios Canarios. La Laguna 2014 315-345.

Autógrafos:

PALENQUE, Marta:

__ El autógrafo de la carta de Gustavo Adolfo Bécquer a Juan José Bueno y otras epístolas relativas a su familia», en "Boletín de la Biblioteca de Menéndez Pelayo" Año LXXXIV, enero-diciembre (2008) 241-261.

—-Una carta inédita de Rubén Darío al conde de las Navas. Darío, objeto de coleccionismo (autógrafos, álbumes y tarjetas postales), en "Journal of Hispanic Modernism", $\mathrm{n}^{\circ} 7$ (2016), 148-170.

WAGNER, Klaus:

_-Preocupaciones bibliográficas de Juan Nicolás Böhl de Faber (A propósito de dos cartas desconocidas del literato alemán), en “Dicenda. Cuadernos de Filología Hispánica” 1 (1982) 209-217.

- De libros y bibliófilos. A propósito de seis cartas autógrafas, en "Mosaico de varia lección literaria. Homenaje a José María Capote Benot". Sevilla, Universidad de Sevilla, Departamento de Literatura Española 1992, 221-229.

42 Hay un estudio sobre otras cartas de Gestoso que por su importancia debe ser mencionado aunque realmente no proceden de su legado a la Colombina: LÓPEZ DETORO, José: Dos cartas inéditas de Menéndez Pelayo sobre una controversia arqueológica sevillana», en“Revista de Archivos, Bibliotecas y Museos", Tomo LXII (1956), 197-210. 


\section{ANEXO 2: RESUMEN DEL FONDO GESTOSO}

Sigue a continuación un compendio de lo expuesto en las páginas precedentes pero agrupándolo -y sintetizándolo- según los distintos formatos en que se divide este legado. Todas las imágenes digitales que aquí se mencionan pueden consultarse en la Sala de Lectura de la Biblioteca Capitular Colombina. Los documentos u obras sueltas que se van digitalizando no se relacionan en este apartado.

Papeles Varios impresos:

- Volumen total: 174 tomos clasificados en tres tamaños: $8^{\circ}\left(62\right.$ tomos), $4^{\circ}(78)$ y $2^{\circ}$ (34). Encuadernación en holandesa con lomos y puntas en piel roja.

- Medios de información:

- Inventarios mecanografiados de 1920, 1921 y [1922], consultables en formato digital.

- Transcripción y revisión de estos inventarios, disponibles en papel y formato digital. ${ }^{43}$

- Copias digitales: de los inventarios.

Papeles Varios de manuscritos e impresos:

- Volumen total: 41 tomos en tamaño gran folio encuadernados en pergamino.

- Medios de información:

- Inventario mecanografiado de 1919, consultable en formato digital.

- Transcripción del inventario, disponible en papel y formato digital.

- Fichero manual por orden topográfico. De cada tomo hay fichas individuales con la descripción de cada documento u obra.

- Catálogo de Pedro Cómez Ramos.

- Índices de los 14 tomos que sí lo incluyen, en papel y formato digital.

- Copias digitales:

- Inventario de 1919.

- Catálogo de Pedro Cómez.

- Índices de los 14 tomos.

- Tomo II completo.

Monografias:

- Volumen total: unos 1000 volúmenes. Encuadernaciones propias de cada libro o reencuadernados por Gestoso con su característico escudete.

- Medios de información:

Para conocer las donaciones hechas en vida consultar:

- Las cartas de agradecimiento de la Biblioteca, conservadas en sus tomos de Correspondencia y otras noticias del Archivo de la Catedral de Sevilla.

- Libro copiador de comunicaciones de la Biblioteca Capitular (con datos de donaciones fechadas entre 1885-1902).

43 Se ha detectado las faltas de los tomos 5 y 13 de los Papeles Varios impresos en $4^{\circ}$. 
- Libro registro de entrada de la Biblioteca (donaciones realizadas entre 1915 y 1941, si incluimos las que también hicieron su viuda y su hija).

- Los listados de las donaciones de 1901 y 1904, consultables en formato digital. En cuanto a los libros donados tras su muerte, ver:

- Inventario mecanografiado de 1920, consultable en formato digital.

- Transcripción y revisión del inventario, disponible en papel y formato digital.

- Copias digitales:

- De los listados de 1901, 1904 y 1920.

- Títulos de Gestoso no recogidos en otros repositorios o con una vinculación especial con la Catedral o la Biblioteca.

\section{Correspondencia:}

- Volumen total: 23 tomos encuadernados en holandesa con piel roja.

- Medios de información: listado de contenido de cada volumen, disponible en papel y formato digital.

- Copias digitales: No está prevista la digitalización sistemática.

Autógrafos:

- Volumen total: 4 legajos.

- Medios de información: listado de contenido de cada legajo, consultable en papel y formato digital.

- Copias digitales: cuadernillo del legajo $4^{\circ}$ titulado: Notas de escrituras curiosas entresacadas de los Índices y legajos del Archivo General de Protocolos.

\section{Apuntes:}

- Volumen total: 16 tomos de Apuntes, numerados del 1 al 14 más dos tomos con numeración romana. Encuadernación en holandesa con lomos y puntas en piel roja.

- Medios de información: listado actual de los títulos de los documentos o textos. Algunos tomos tienen índice, que ha sido incluido en ese listado. Consultable en papel y formato digital.

- Copias digitales: No está prevista la digitalización sistemática.

Títulos honoríficos:

- Volumen total: 3 tomos, Títulos honoríficos I y II y Méritos y Servicios, encuadernados en piel.

- Medios de información: índice original en cada tomo.

- Copias digitales: de los índices.

Sus memorias «De historia sevillana. Páginas de mi vida»:

- Volumen total: 2 tomos, encuadernados en pergamino.

- Medios de información: índice original de cada tomo (inserto en el anexo 3).

- Copias digitales: Los dos tomos completos. 


\section{ANEXO 3: ÍNDICE DE LAS MEMORIAS DE GESTOSO}

Se detalla a continuación el contenido de los dos tomos de las Memorias de Gestoso tituladas De historia sevillana. Páginas de mi vida con indicación de la foliación actual:

TOMO I:

Introducción (h.1)

Cuadro de la Virgen del Carmen en la Catedral (h.55)

Lápida de D. Iñigo de Mendoza (h.66v)

Tablas alfonsinas (h.67)

Puertas antiguas del Ayuntamiento (ver Apéndice $1^{\circ}$ ) (h.68)

Proyecto de Museo Arqueológico Municipal (ver Apéndice 2) (h.71v)

Restauración de la Capilla de la Piedad en Santa Marina (h.72v)

Limpieza de la portada de la iglesia de San Marcos (h.73)

Cáliz de la iglesia de San Vicente (h.73)

Pendón de la ciudad (ver Apéndice $\left.3^{\circ}\right)(\mathrm{h} .74 \mathrm{v})$

Servicios en favor de la Biblioteca Colombina (ver Apéndice $4^{\circ}$ ) (h.77v)

Cerámica de Triana (ver Apéndice 5) (h.83v)

En honra de Gustavo Adolfo Bécquer (h.100)

El cuadro de S. Julián obra de Juan Sánchez de Castro (h.116)

Columnas de la calle de los Mármoles (h.120)

Laude sepulcral de D. Perafán de Ribera (h.122)

En favor del Archivo de Indias (ver Apéndice 6º (h.124)

Bandera de los sastres (h.157)

Ordenación del archivo del Alcázar (h.161)

Los epitafios de los Marqueses de Montemayor (h.167)

Restauración del torreón de Sto. Tomás también llamado del Homenaje (ver Apéndice $7^{\circ}$ ) (h.169)

Las fiestas del IV Centenario del descubrimiento de América (h.171)

Monumento sepulcral de D. Antonio Martín Villa (h.175)

Restauración de las Casas Capitulares y su verja defensiva (h.179)

Exposición retrospectiva de pintura (ver Apéndice $8^{\circ}$ y 9º (h.198)

La restauración de la Torre del Oro (h.202)

La exposición de bordados antiguos (h.206)

Museo de Pinturas (h.210)

Las tablas de los caballeros de las Órdenes militares depositadas en el Museo de Pinturas de esta ciudad (h.218)

La tabla de San Telmo propia de esta Universidad Literaria (h.258)

Excavaciones en Santiponce (h.265)

Coronación de la Virgen de los Reyes (ver Apéndice 10) (h.271)

La Capilla del Seminario (h.272)

La Exposición de retratos antiguos (no en el índice) (h.280)

Datos para la historia de la Capilla de S. José y del templo parroquial de Sta. Catalina (h.282)

El archivo de los plateros sevillanos (h.304) 
La estantería del Archivo Municipal destinada a la Sección de Privilegios y de Actas (h.309)

El retrato de Mirtilo Sicuritano (h.315)

Las murallas romanas de la Macarena (h.319)

Los Archivos de Protocolos (h.332)

Requisa de cuadros en la Catedral de Sevilla en 1908 (h.387)

Donativos que he hecho a Establecimientos públicos de esta ciudad (h.388)

TOMO II. Apéndices:

$1^{\circ}$.- Adición a las notas de la restauración de las hojas de las puertas del Ayuntamiento (h.1)

$2^{\circ}$.- Adición a las notas del Museo Arqueológico Municipal (h.3)

3.-- Adiciones al Pendón de Sevilla (h.7)

$4^{\circ}$.- Adiciones a la Colombina (h.37)

$5^{\circ}$.- Adiciones a las obras de cerámica contemporánea (h.43)

[6 .- Archivo de Indias] Aunque según el índice hay un apéndice 6 en el Tomo II de las Memorias, en su lugar se encuentra una hojilla inserta con esta nota: «El Apéndice 6. Archivo de Indias ha pasado al texto a fin de reducir el volumen de estos Apéndices fols. 43 al 49» (h.68)

$7^{\circ}$.- Apéndice a la restauración del Torreón de Santo Tomás (h.69)

8.- Catálogo impreso de la exposición retrospectiva de pinturas (h.75)

9'.- Discurso pronunciado en la solemne inauguración de la Exposición retrospectiva de pintura... (h.87)

$10^{\circ}$.- Coronación de la Virgen de los Reyes (h.120)

$11^{\circ}$.- Apéndices a las Excavaciones de Santiponce (h.321)

Lápida de San Hermenegildo (h.352) 


\section{APÉNDICE DOCUMENTAL}

Por su interés para conocer la relación de Gestoso con la Biblioteca Capitular Colombina, se incluyen en este trabajo los dos textos que le dedica en sus Memorias, tanto en el T. I, que titula Servicios en pro de la Biblioteca Colombina (h. 77v-83v), como en el II, el Apéndice 4, Adiciones a la Colombina (h. 19-42v). En José Gestoso y Sevilla. Biografía de una pasión (pp. 421-439) he publicado el texto introductorio de esas Memorias y en él también menciona en varias ocasiones la Biblioteca. Con él se completan todos los recuerdos que Gestoso quiso conservar sobre este centro.

\section{Servicios en pro de la Biblioteca Colombina}

"Larga va a ser esta parte de mis Apuntes, pero rica en noticias que puedan aprovechar algún día, para los curiosos que deseen conocer a fondo lo ocurrido en tan famoso Establecimiento en estos últimos años. En los comienzos de 1885 asistíamos cuotidianamente a estudiar en él D. Francisco Tubino, un escritor ilustre gaditano cuyo nombre callo por caridad, por más que tan merecido que lo sacase a la plaza pública con este sambenito, y yo. Ocupábase el primero en allegar materiales para su historia de D. Pedro I y el segundo, por más que decía que su objeto era el de reunirlos para esclarecer el sitio en que ocurrió la batalla del Guadalete, dedicase durante muchos días a curiosear los libros de D. Fernando Colón y los códices más notables que posee la Biblioteca. No tardó mucho tiempo en que se tocasen los funestos resultados de lo que el gaditano hacía, quien emulando con el bibliopirata extremeño, lo sobrepujó en su amor bibliográfico, por el estilo del galeote que dijo a D. Quijote, iba condenado al remo por haberse enamorado de una canasta de color atestada de ropa blanca; pues hizo un verdadero saqueo de los tomos de Varios de la Fernandina, arrancando cuantos folletos conceptuó que podrían valerle algunos ochavos, que de bonísima gana ponía en sus manos un rico coleccionista que vive muy cerca del Alcázar, persona tan atildada en el esterior (sic) de su persona, como descuidada en su parte moral, y por tanto de garguero tan ancho, que no hay negocio de antigüedades por delicado que sea en que él no intervenga. Pues bien, este gentilhombre, y un pobre diablo traficante en joyas, coleccionista de libros y hábil acaparador de cuanto topan sus ojos se pusieron al habla con el gaditano y por cuatro ochavos adquirían lo que este robaba, bien es verdad que apretado por el hambre y la miseria tan malas consejeras. Hecha la presa, el caballero elegante remitía a París, rellenando los huecos de las cajas de tapices, esculturas, azulejos, con los folletos de la Colombina, y claro es, como todos ellos eran escojidos (sic), bien pronto cundió por la gran metrópoli y entre los afanosos rebuscadores, la noticia de la llegada de tanta preciosidad bibliográfica. No faltó quien diese la voz de alarma y la prensa parisiense trajo a España noticias detalladas de los libros vendidos y hasta de su procedencia. No estaban aquí algunas personas tan ignorantes de lo que ocurría, asegurábase de pública voz, que parte de los primeros folletos enviados a París se ofrecieron en venta a la Biblioteca nacional, y como algunos de ellos conservasen todavía el sello de la Colombina, honradamente obrando el Director de aquel Establecimiento, dio noticia de lo que ocurría, a su colega el Sr. Arbolí, 
encargado por el Cabildo de la custodia de la Colombina. Difícil es hacer concebir a las personas que ignoran lo que ocurrió, la determinación tomada por el celosísimo canónigo, en vez de procurar el rescate de aquella riqueza, temeroso de que la opinión le culpase por descuido, contestó al bibliotecario de París que no era cierto se hubiesen sustraído libros de la Colombina, y que el hecho de que tuviesen el sello era, sin duda, para [sorprender] a los compradores, dando mayor a su mercancía. El francés bañose en agua de rosas y se dejó sorprender adquiriendo los folletos para la Biblioteca. El escándalo mientras tanto llegaba al cielo, y los periódicos sevillanos publicaron cartas de Mr Henry Harrisse dando los más minuciosos pormenores de todo este asunto, en que tan mal parado quedaba el nombre de España. Los principales artículos impresos entonces por los periódicos, ya en pro ya en contra, puede verlos el curioso reunidos por mí, a continuación del folleto de Harrisse Grandeur et decadence de la Colombina que tradujo el Sr. Guichot y que yo imprimí a mis expensas ([Un] vol.8 Sevilla El Universal - 1886).

Sospechaba yo, cuando diariamente acudía a la Colombina, que el docto gaditano al examinar los libros de D. Fernando, buscaba ocultamente algo, y que sus intenciones eran / otras de las que el exterior demostraba. La inquietud y presteza con que repasaba los volúmenes, las señales que en ellos dejaba puestas por medio de registros de papel, la coincidencia buscada por él de procurar que su hora de irse a almorzar no fuese la misma a la que nos íbamos Tubino y yo, para quedarse solo en el último salón de la Biblioteca, que era donde por especiales consideraciones trabajábamos, y por último, la circunstancia de que nunca le vi tomar apunte o nota de ninguno de aquellos volúmenes; todo esto comenzó a extrañarme, viniendo a corroborar mis sospechas el siguiente lance. Hallábame un día en la Colombina, y como sintiese alguna incomodidad determiné dejar / mis estudios aparte por aquel día y salir a distraerme. ¿Dónde va V. me preguntó el bibliopirata? - No me siento bien, le conteste, y voy a espaciarme por ahí un rato. Pues yo, replicó, tengo hoy muchos deseos de trabajar y pienso estar aquí todo el tiempo posible - Pues hasta mañana...

Una vez en la calle, ocurrióseme ir a casa del elegante anticuario de marras: recibiome en su despacho, cuya puerta de entrada la tiene por el patio, y me senté, precisamente de espaldas, a la dicha puerta. ¿Qué hay de nuevo? Preguntome aquel.- Nada, le contesté; hace tiempo que no adquiero ningún objeto de interés... Pues yo tengo más suerte que V. y en prueba de ello vea / V. mis últimas adquisiciones. Levantose de su asiento y de una caja de hierro sacó varios folletos franceses e italianos, góticos, entre ellos recuerdo perfectamente que había uno en $4^{\circ}$ intitulado... Jean de París. No sé por qué ocurrióseme que aquellas preciosidades podrían ser de la Colombina: repasé sus hojas buscando las notas autógrafas de D. Fernando, y en efecto, en algunos vi señales de raspaduras, y en otros restos de escritura, que no habían podido hacer que desapareciesen. Oculté las impresiones que estaba experimentando, y el feliz poseedor confiándose más, me enseñó una hoja de vitela en que se hallaba pintada la Crucifixión del Señora y que /enseguida conocí del Canon del Misal de la Colombina, que me parece es el llamado del Cardenal Mendoza, de cuya misma hoja tengo calcos hechos, y por tanto, no cabía la menor duda de su procedencia. Ya entonces no pude contenerme y hablé claro al gentilhombre, quien se sorprendió o simuló sorprenderse de mis revelaciones; 
mas como aún lo dudase, ofrecile llevarle los calcos, como con efecto así hice, uno o dos días después. Quedábanme aquel día reservados el contento y satisfacción de descubrirlo todo pues apenas hacía media hora que había entrado en el despacho de mi amigo, oigo a mis espaldas la voz del portero que dice"Señor, el caballero que trae a V. a vender los libros está ahí - Que pase, contesto aquél: volví la cara hacia la / la puerta y me encontré con la del bibliopirata, que al verme, demudase, y materialmente tembloroso, con el sombrero en la mano, avanzó a saludarnos, y sin poder contener ni dominar su emoción. No me cupo pues duda alguna del juego que ambos traían, y convencido ya, para no hacer más violenta la situación del gaditano, despedíme y salí. La suma de mis sospechas anteriores, corroboradas por este lance providencial, quedaron reservadas por mí, pues aun cuando eran bastantes para que yo diese la voz de alerta en la Colombina, era el asunto tan grave, que después de oído el parecer de mi amigo D. Fernando Belmonte decidí seguir su consejo y callar. Poco tiempo después los periódicos comenza/ron el fuego de guerrillas, hasta descubrirse todo. Yo no cesaba de solicitar de mi elegante anticuario la devolución de la lámina del Misal, hasta que conseguí que me la entregase, [teniendo] el gusto de completar el hermoso libro, que sin mis gestiones hubiese quedado falto de su más precioso ornamento. Descubierto ya todo, procuré indagar qué otras personas tenían libros y folletos de la Colombina, de los primeros que vendió el bibliopirata al traficante en joyas, y averigüé que mis amigos D. José Calvo y D. Enrique Leguina $(\mathrm{I})^{44}$ habían comprado algunos, los de aquel por mi intervención fueron también devueltos. Por último diré que los calcos del Misal que me sirvieron para demostrar al elegante / la procedencia de la hoja del canon pueden verse en el tomo de mis Apuntes que tratan solo de la Catedral.Veanse las Adiciones".

\section{ADICIONES A LA COLOMBINA}

"Van unidos a este Establecimiento, honra de Sevilla, muy gratos recuerdos de mis primeros años, por lo cual, le he tenido siempre profundo cariño. No puedo olvidar que desde pequeño complacíame en extremo que mi buen padre, íntimo amigo del oficial bibliotecario, el inolvidable D. José María Fernández Velasco, me llevase a visitarlo, pues no sé por qué, la figura enjuta de aquel viejecito, que formaba armónica pareja con la de su ayudante, más viejo aún, atraíame, pues el uno o el otro me enseñaban libros con hermosas estampas y llegaban en su bondad a poner en mis manos, sacándola del estante donde en mi niñez se conservaba (I ${ }^{45}$, la espada que usaran, al decir de las gentes, por aquel entonces, Fernán González y Garci Pérez, que era una de mis mayores satisfacciones tener en mis manos aquel fuerte acero que habían esgrimido ambos legendarios héroes.

Muchas veces íbamos en compaña de D. Juan José Bueno, amigo del alma de mi padre, y allí nos tropezábamos con D. José María Asensio. Reunidos hablaban, principalmente, de las obras para mejorar la Biblioteca, de los retratos de hijos ilustres de Sevilla que por entonces se estaban pintando, con destino a la misma,

44 (I) Este devolvió dos o tres folletos, regaló algunos a D. Antonio Cánovas y se quedó con otros.

45 (I) "Posteriormente se hizo la urna de caoba y cristal en que hoy se custodia". 
obra meritoria, por la cual se interesaban, singularmente, Fernández y Bueno. Otras veces el buen bibliotecario daba cuenta de algún nuevo libro impreso o manuscrito que había encontrado, procedente de la Fernandina; traíase el libro, examinábase, hoja por hoja, notando las particularidades que ofrecía, si estaba o no registrado por Colón, si tenía apostillas marginales del eximio bibliófilo y además de Loaysa o Gallardo, en suma; estudiábanlo bajo todos sus aspectos felicitando al celosísimo D. José por el buen hallazgo. Otras veces Asensio hablaba de sus proyectos de publicaciones, del hallazgo de un códice inédito de poesías, de nuevos datos que tenía reunidos acerca de tal suceso histórico o del autor de ciertas poesías, hasta entonces erróneamente atribuidas a determinado ingenio, y más de una vez llegaba a tomar parte en la amenísima plática, un señor alto, delgado con nariz aguileña, ojos pequeños y vivos, con patillas canas y voz ronca que se llamaba D. Francisco de Borja Palomo... Yo me embobaba oyendo hablar a aquellos señores de cosas, que si bien eran para mí desconocidas, despertaban mi simpatía y mi curiosidad. Allá en lo hondo teníales envidia... me hubiese gustado hablar como ellos de libros, códices, incunables, historias, crónicas, poesías y todo aquel maremágnum que traían a colación de cosas divinas y humanas, pasadas y presentes. Pasaron años, era yo un mozalbete y por cuenta propia acudía a la Colombina, donde D. José Fernández y el anciano D. Nicolás, su lugarteniente, me recibían con la mayor bondad y entonces dime a leer las Crónicas de los reyes castellanos (las hermosas ediciones de Sancha) y poco a poco deseoso de conocer la historia de nuestra Catedral pasaron por mi mano, primero los grandes historiadores sevillanos, luego las relaciones, apuntes, memorias y notas de los curiosos y eruditos. Yo quería saber quién había construido aquella gigantesca mole, quien pintara las hermosas vidrieras, quienes los cuadros que sorprendían mi corta inteligencia; las estatuas que casi ocultas en sus hornacinas me imponían al fijar en mí sus pupilas; quería conocer la historia der aquel mundo misterioso, que todos sus secretos se me revelasen...Y pasaron años y durante ellos ¡cuántas veces, en vez de asistir en mis clase universitarias, de oír las fastidiosas conferencias de Derecho, de Economía política y de Procedimiento, me iba a la Colombina a revolver los folios de las Memorias históricas de Muñana, las Cartas de San Martín, los Apuntes de Loaysa y de Gálvez!...

Con lo dicho queda esplicado (sic) mi cariño por la Colombina ¿qué extraño, pues, que llevando conmigo tales recuerdos sienta hacia ella tan viva simpatía? ¡Ah! Si yo hubiese contado con grandes recursos: ¿quién más que yo hubiese realizado las mejoras de que tanto ha necesitado siempre?

Quise sin embargo en mi pobreza, cuando ya las arrugas surcaban mi frente, dejar un testimonio de mi cariño a la famosa Biblioteca, donde habían pasado los mejores años de mi juventud y para ello dispuse en mi testamento otorgado ante

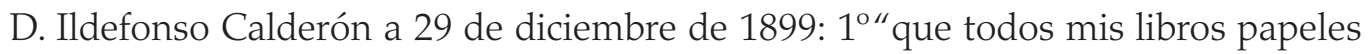
pasasen después de mi muerte a la Colombina y $2^{\circ}$ que si el local lo permitía, mis herederos costeasen un estante, invirtiendo en su hechura quinientas pesetas, donde se reuniesen unos y otros, mas como posteriormente el Cabildo Catedral dispuso ampliar la Biblioteca con el nuevo salón que lleva el nombre de la Ynfanta María Luisa Fernanda, instalando en él al hermosa estantería de caoba y cedro que procedente de la librería del palacio de S. Telmo, donó a la Corporación ecca. dicha Señora, como me hubiese sido ofrecido uno de los mencionados estantes 
para depósito de mis libros por los Sres. Mayordomos de Fábrica y canónigo bibliotecario, contribuía al costo de las obras del nuevo salón con las referidas quinientas pesetas, por cuyo donativo el Cabildo me dio gracias según consta del oficio que aquel me dirigió en 6 de febrero de 1900. Contando ya con un sitio destinado para depositar mis libros, hice mi primer donativo de ellos en 8 de julio de 1902, que fueron 317 volúmenes y desde aquella fecha hasta el día (1913) no ceso de enviarlos anualmente, al punto, que, hoy calculo tener entregados unos 500, quedando siempre en vigor mi disposición testamentaria de que se entreguen a mi muerte cuantos libros y papeles existan al ocurrir ésta.

$\mathrm{Al}$ tratar en estos apuntes de lo que he hecho en honra de Gustavo Adolfo Bécquer, queda descrito el via-crucis que recorrió el retrato del inmortal poeta que regalé a la Colombina a fines de 1879 o en los comienzos del 80, cómo lo aceptó el Cabildo y porqué dispuso quitarlo y esconderlo, cómo lo reclamé y deposité en la Sociedad Económica donde estuvo hasta 1909 en que desaparecidos del mundo de los vivos los Señores canónigos que se opusieron a que figurase en la colección de retratos de sevillanos ilustres hube de donarlo nuevamente dándome por él gracias el Cabildo en (2 de diciembre de 1908) 11 de agosto de 1909.

Los merecimientos del ilustre sevillano D. José María Asensio y Toledo, con quien, no obstante la diferencia de edad, me unió el más cariñoso afecto, me estimularon a que se rindiese justo tributo a su memoria, pues en la conciencia de todos sus contemporáneos está que le sobraban títulos para ser contado entre los más ilustres sevillanos, cultivadores de la historia y de las letras patrias. Así pues, mandé hacer su retrato, que figura en los muros de la Colombina, y por el cual me dio gracias el Cabildo en 24 de octubre de 1911.

Esto es cuanto he podido hacer en obsequio de la famosa Biblioteca, de este centro de cultura tan grato para mi corazón. Poco es, bien lo reconozco, pero, consuélome pensando en que aquellos a quienes sobran medios, menos, nada, han hecho ¿Quién se acuerda hoy de ella? ¿Quiénes acuden a estudiar sus papeles viejos, cuando en la Prensa diaria de la capital, sin contar con la ilustradísima de la Corte, serena, imparcial, verídica, hallan en sus columnas la más varia, amena, instructiva y profunda enseñanza, como no puede ser menos dada la falange de brillantes ingenios que forman la plana mayor de las redacciones?

No es extraño pues que nuestras bibliotecas se hallen desiertas y más la Colombina que por su índole especial no se compadece con las aficiones y gustos de los intelectuales modernos, que al hablar de ella dicen que está fosilizada." 
